\title{
Application of Data Mining Using Artificial Neural Network: Survey
}

\author{
Muhammad Arif ${ }^{1,2}$, Khubaib Amjad Alam ${ }^{1}$ and Mehdi Hussain ${ }^{1,3}$, \\ ${ }^{1}$ Faculty of Computer Science and Information Technology, University of Malaya \\ 50603 Kuala Lumpur, Malaysia \\ ${ }^{2}$ Computer Science Department, Comsats Institute of Information and Technology \\ Islamabad Pakistan \\ ${ }^{3}$ School of Electrical Engineering and Computer Science, National University of \\ Sciences and Technology, Islamabad Pakistan \\ arifmuhammad36@siswa.um.edu.my,khubaibalam@siswa.um.edu.my, \\ mehdi141@siswa.um.edu.my
}

\begin{abstract}
The use of neural network is very wide in data mining due to some characteristic like parallel performance, Self-organizing adaptive, robustness and fault tolerance. Data mining models depend on task they accomplish: Association Rules, Clustering, Prediction, and Classification. Neural network is used to find pattern in data. The grouping of neural network model and data mining method can greatly increase the efficiency of data mining methods and it has been broadly used. Different algorithms have been discussed for optimizing the artificial neural network (ANN). ANN combines with other algorithms to find out the high accurate data as compare to traditional algorithm. The role of ANN using data mining techniques is playing an important role in forecasting or prediction about games and weather. This produces high accurate predictions than that of traditional algorithm. Data mining approaches using ANN can also work well. ANN is a highly class algorithm which can be accelerated using neuron. The result of which will produce a high speed up ANN. ANN can also be used for the purpose of extracting rules from trained neural networks.
\end{abstract}

Keywords: ANN; Data mining; Application; Classification

\section{Introduction}

The volume of data store in database increase rapidly and huge amount of information are hidden. The technology of mining the information from the huge volume of data (database) is called Data Mining. Neural network is very appropriate for solving problems of data mining because of its characteristics of good robustness, Self-organizing adaptive, parallel processing, and fault tolerance. Neural network have been used in many business application for pattern recognition, prediction and classification. Neural network have high ability for noisy data and high accuracy $[1,2,6,25]$. Neural network are non-linear statistical data modeling tools. This can be used to model complex relationships between input and output or to find patterns in data. It is very suitable for solving problems of data mining because it characteristic of parallel processing, high degree of fault tolerance, good robustness [7, 2]. The method of neural network is used for feature mining, pattern recognition, Clustering and classification. The model of neural network is dividing into three types such as feed-forward network, feedback network and self-organization network [1]. The huge amount of medical data is available but there is a lack of data analysis tool to extract useful knowledge from it. Unfortunately all doctors are not expert in all field of medical. Clinical results are often ready base on doctor's awareness and 
experience rather than on the knowledge masked in the database. Data mining have the ability to produce a knowledge-rich situation which can aid to improve the worth of clinical decision, due to this reason automatic medical diagnoses system is very useful by fetching all of them together. Genetic Algorithm is used to reduce the actual size of data which is enough for heart disease [2].Artificial Neural Networks offer qualitative methods for business and economic systems that Traditional quantitative tools in statistics and econometrics cannot quantify due to the complexity in translating the systems into precise mathematical functions [3].Heart disease professional stores significant amounts of patient's data. It is necessary to scrutinize this data set to extract valuable knowledge. Knowledge of risky factors which are linked with the heart disease helps the care professional to identify the patients which have high risk of heart diseases [4]. In the market basket when a new transaction is added then for refreshing the ranking table we apply the artificial neural network. By data envelopment analysis it prevents to repeat all the process of problem. Minimum support and minimum confidence are the two factors of an association rule which determine the strength of a rule[5]. The combine tactic of Artificial neural network based network inference and Artificial neural network base data mining we have recognized 6 genes that associate with ER system in breast cancer. Only 4 are strongly associated with ER status [8].The new ways to find information from news through internet and apply interest rate on the basis of this information, so write a survey on data mining and ANN based applications. According to prior knowledge it retrieves and search information of NEWS on internet, and then we apply this information on the neural network model for the interest rate prediction [9]. The data mining is used to explore the potential factor of huge amount of data but still the preterm birth is still unclear. The different preterm risks factor discussed in the related work. The goal of this survey is to evaluate knowledge from raw data. Some parameter which effect the performance of neural network such as quality of data preprocessing and neural network structure are discussed clearly in the literature.

The remaining paper is divided into different section. Section 2 discussed about usage of neural network and data mining. In section three we discussed about the use of data mining in medical diagnosis. In section four we discussed about the use of classification and neural network. In section five we discussed about the use of neural network approach and data envelopment analysis. In section six we discussed about the use of neural network and data mining in Information Technology. In Section 7 we discussed about the use of artificial neural network and data mining. In Section 8 and 9 covered discussion and conclusion.

\section{Neural Networks and Data Mining}

In this paper [1] the author's studied the use of neural network in data mining. It has been observed that the use of neural network is very wide in data mining due to some characteristic like parallel performance, Self-organizing adaptive, robustness and fault tolerance. It is used for business applications like Classification, pattern recognition, Prediction. The method of neural network is also used for feature mining, pattern recognition, Clustering and classification. The model of neural network is divided into three types such as feed-forward network, feedback network and self-organization network. It uses neural network to find pattern in data. The categorization of Data Mining models depend on task they accomplish: Association Rules, Clustering, Prediction, and Classification. The process of Data Mining is composed of three phases: Data Mining, Data Preparation, Expression and interpretation. In three phases the data mining is based on neural network like Data preparation, Rule Extracting, Rules Assessment. Companies have been collecting data for decades, building massive data warehouses in which to store it [3]. Even though this data is available, very few companies have been able to realize the actual value stored in it. The question these companies are asking is how to extract this 
value. The answer is Data mining. Effective Data mining required four things: right data, right tool, high quality, and sufficient sample size. Neural network also play important role to solve problem of data mining. Its characteristic are robustness, parallel processing, fault tolerance, distributed storage, high storage [3]. Artificial Neural Networks offer qualitative methods for business and economic systems that Traditional quantitative tools in statistics and econometrics cannot quantify due to the complexity in translating the systems into precise mathematical functions. Hence, the use of neural networks in Data Mining is a promising field of research especially given the ready availability of large mass of data sets and the reported ability of neural networks to detect and assimilate relationships between a large numbers of variables. For gaining knowledge in data mining the following method are used, 1) Statistical Method, 2) Production Rule IF - THEN, 3) Genetic Algorithms, 4) Decision Tree, 5) Artificial neural Network [3].

In this paper [6] it has been reported that the continuous development of database technology and the volume of data stored in database increase rapidly and huge amount of information are hidden. The technology of mining the information from the huge volume of data (database), is called Data Mining. Neural network is very appropriate for solving problems of data mining because of its characteristics of good robustness, Self-organizing adaptive, parallel processing, and fault tolerance [6]. Neural network have been used in many business application for pattern recognition, prediction and classification. Neural network have high ability for noisy data and high accuracy. For the training of artificial networks it needs supervised learning, Unsupervised Learning, Reinforcement Learning. The neural network can be divided into following type recurrent neural network, Feed forward neural network. The algorithm used is Back propagation Algorithm [6]. In this paper [7] the author reported that in data mining the application of neural network is very wide. Neural network are non-linear statistical data modeling tools. This can be used to model complex relationships between input and output or to find patterns in data. It is very suitable for solving problems of data mining because it characteristic of parallel processing, high degree of fault tolerance, good robustness. Data mining process is composed by three main phases: Data preparation, Rule Extracting and Rules Assessments. There are only two types which based on Data mining: self-organization neural network and fuzzy neural network. The technique use for implementation is Effective Combination of Neural Network and Data Mining Technology, Effective Combination of knowledge Processing and Neural Computation and input/output interface [7]. The grouping of neural network model and data mining method can greatly increase the efficiency of data mining methods and it has been broadly used [7]. This study [11] explains that due to the advances of information technology the field of business intelligence and data mining arose. The goal of BI/DM is to evaluate knowledge from raw data. They presents $\mathrm{r} /$ miner library which make it easy to use the $\mathrm{R}$ tool to solve the task of DM supervised [11]. For Neural network (NN), flexible and SVMs and nonlinear learning technique, due to predictive performances they are promising. Overall the results obtain were competitive. In particularly the NN for regression ones and SVM model for the classification task [11].

In this paper [12] the author report that the back propagation method is used for supervised neural network and was develop for metal alloys. For the training of artificial networks it needs supervised learning, Unsupervised Learning, Reinforcement Learning [12]. The neural network can be divided into following type recurrent neural network, Feed forward neural network. The algorithm used is Back propagation Algorithm [12]. This paper [13] explains about the R tool which is an open source and is extensively used for data analysis. They present $\mathrm{r} /$ miner library in this work which easily use the $\mathrm{R}$ to solve the DM regression and classification tasks. For SVMs and NNs this library is principally suited. For Neural network (NN), flexible and SVMs and nonlinear learning technique, due to predictive performances they are promising. Overall the results obtain were competitive [13]. In particularly the $\mathrm{NN}$ for regression ones and SVM model for the 
classification task. The method used is DM, and BFGS algorithm and the model used was SVM and NN. R/ miner and CRISP-DM were the two tools which were used in this paper [13]. This study [14] describes that for time series forecast different computation techniques are used. Linear models are also used like ARMA (Auto-regression moving Average) and AR (Auto-regression) and non-Linear like Neural Network. One of the techniques used for time series analysis is Neural Network. Some parameters affect the performance of neural network such as quality of data preprocessing and neural network structure [14]. For obtaining the optimal neural network there is a need to explore these parameters. The data mining process which uses neural network for time series are further explained in three steps.

- Setup of neural network (hidden layers, number of input entries, neuron in hidden layers.

- Sample data Preparation for cross validation and training.

- Statistical analysis of time series.

The aim of the neural network controller is to ratify all cartridges as a recurrent workflow for finding an ideal neural network for time series forecast it is the responsibility of statistical cartridge to remove the outlier and the classification of the time series. The important activity for the time series is the outlier removal. There are many methods for the normalization the data such as Z-score, min and max normalization and normalization by decimal scaling. In order to implement different neural network cartridge, it is important for the exploratory configuration to specify the meta-data information then the controller to explore different neural network [14]. It is concluded that obtaining neural network was robust for both pseudo-stationery and stationery time series [14]. The main aim of data mining [15] is to extract knowledge from huge amount of data. The well-known strategies to data mining include neural and symbolic model. Fuzzy neural network technique is used as channel between symbolic and numerical data representation. By using fuzzy logic we can express knowledge in such a way which is natural for the people to understand. It increases the speedup of convergence of the network. It decreases the rate of computation as its start with minimal rule base which increase only when a data is required by new input, it frequently remove the unrelated inputs, and condition rules which are unable to match the data any more. The proposed FNN network comprises of four layers which are Input Layers, Rule Layer, Output Layer, Input membership function layers [15]. Due to human error and statistical fluctuations data may contain a certain level of noise. In this paper the ratio of noise is reducing up to great amount it's due to capability of neural network to deal efficiently with the noisy data [15].

The main theme of this paper [16] is to illustrate and introduce a methodology of neural network for resolving problems with many additional free parameters than the data point to maintenance Data Strip mining problem. Data Strip Mining mine predictive models from data sets which has comparatively few data point and large number of potential input. This method uses neural network sensitivity analysis to find that which interpreters are mostly used in the problem [16]. To determine the most important input to a system Neural Network sensitivity analysis was used as method, which allows removing some of the least critical input. To accurately determine the different neural model of the same system the author used a model cross validation as a method [16]. This methodology offers few weakness and several benefits. When the number of candidate input increase as the number of data points it produces a good predictive model. On this result, for future research there are many directions in this area [16]. In this paper [17] the author tells us that data mining is a process which uses different variety of data analysis tool to determine relation and patterns in data that is used for creating prediction. To model an output on one or more input variables a technique called supervised data mining technique 
is used, and these kinds of models are used to forecast or predict future cases. This article compared two supervised method decision tree and artificial neural network [17]. The main aim of this paper is to study that how in meal pattern analysis; two supervised data mining technique are used. The dataset which is used is NSIFCS. In Artificial neural network (ANN) a major criticism are BLACK BOX approach, because they have limited ability and not very transparent to identify explicitly possible causal relations. The network input is one of the approaches to solve [17].

In this paper [18] the author explains about the important task of data mining in Classification rules. A hybrid approach is presented which integrate the neural network and rough set to pit the classification rules from huge datasets. Without any classification information loss a decision table is first reduce by removing redundant attributes. So to delete the noisy attribute in the table a neural network is trained. Those objects of also removed from the table which cannot be classified accurately by network. By reducing decision table by rough set a classification rules are generated [18]. We applied the present hybrid approach to the classification series of problems which include real world problems and artificial world problems. The comparison experiment describe that our approach are more concise than the traditional base approach. The robustness shows that the current approach can work awesome under different level of conditions [18]. This study [19] is carried out to show a number of application areas such as economy finance, experimental sciences, monitoring of electrical distribution network. To discovered pertinent knowledge in data the analysis of such data is important. In electrical power network the current signals and voltage reveal fluctuations in phase, amplitude, and frequency due to solid state device operation which are used for regularly used for power control [19]. The swell and sag occur when the Increase and decrease are known in voltage signal. When momentarily the signal amplitude becomes zero then it is the state of interruption. It's used Wavelet-based method. The algorithm uses in this paper are Gradient descent Algorithm, RLS (Recursive least-Square), LMS (Least mean square). It uses the approach of S- Transform. The new approach which is used in this paper is beaten as the current technique as far as sensitivity and correctness to noise are concerned [19].

In this paper [22] the author tells us that in data mining techniques neural network is widely used. Multilayer perception is very slow for the high dimensional datasets. In real time data mining the application it is an important draw back for using them, because its requirement is that, it needs answer within a short duration of time [20]. CMAC Neural Network adaptation they have proposed for data mining in this research paper. Which provide guaranteed convergence and fast training time? This paper also defines us that how CMAC adaptation is constructed for data mining, about classification model that is used in data set of real-life. It works on real dataset. The models which were used are CMAC, MLP and C4.5 and the algorithm is CMAC algorithm [20]. In this paper [22] the author tells us about a new method in which DSS is supported based on data mining and neural network. Three subjects have been discussed in this paper. To support DSS how to make use of neural network is the first. And the second one is that, to support DSS how to make use of data mining and the third one is, To support DSS how to make use of neural network and Data Mining. DSS was developed by American scientist Scott Morton in 1970 [22]. Three departments of DSS are discussed they are Knowledge system (KS), and Problem process system (PPS) and language system (LS). The neural network to DSS function is ensuing by scrutinizing the characteristic of problems and neural network of DSS. The large scale parallel distribution processing function, learning function, selflearning of natural language processing system, overcoming the difficulties of infinite recursion and assembled blast, promoting of deciding the ability of DSS and real time processing , Adoptive parallel association reasoning [22]. This paper [26] gives an idea about fraud detection using different algorithms. This paper gives us that how to combine advance data mining techniques with neural network effectively to get a high fraud 
reporting and with a low false alarm speed [26]. The first algorithm that the author has used is mining the symbolic data. This algorithm is based on the idea that misused transactions are seen as a kind of rule [26]. The advantage of this is, combining a number of misuse rules which leads us to shorten the rules and decrease the dependency. The other rules are called mining analog data [26]. These rules are based on dealing with analog data. Here the problem of fraud analysis is based on separating two kinds of classes of events. This algorithm leads us to high fraud detection and high confidence. In last the author used another technique by combining rule based association algorithm and network information in decision network. When this system is used in parallel then this shows error in large amount along with low confidence. Beside that this system is used in sequential as well. The advantage of this system is that the analog data first passes through analog check and then moves forward for sequential check, which leads us to high data correctness and high confidence as well [26]. This paper [27] is based on effective data mining using neural network. The paper shows an approach to find out symbolic classification set of laws by means of neural network. Whereas neural network is first qualified to attain the obligatory precision pace. Furthermore the unneeded link of network is detached by mean of network pruning process [27]. The activation principles of the unseen element in the system are evaluated. This leads us to the classification rules of particular analysis. Research is conducted on this planned approach using a distinct set of data mining difficulty. And the outcome demonstrates that high quality of rules can be exposed from the known data sets [27]. The theme of the study [32] is to make different clusters using data mining technique. He makes use of self-organizing map (SOM) to accomplish his goal. The aim of SOM is to map multi-dimensional input into two dimensional forms. This tactic is used for clustering and classification purpose. The rules are extracted from trained SOM's. Which can then figure the prepositional IF... THEN type system. These effortless set of laws can be easily broken by expert or decision support system and are simply interpretable to an expert. The law signify the trained SOM in cases where clustering has willingly taken place [32]. The important feature of this projected scheme is the underlying exactness of clustering procedure achieved by SOM. In case where the SOM not succeed to readily cluster the facts, the ensuing system will replicate this original inexactness [32].

The motive of this paper [38] is to deal with non-financial and financial ratios of the financial statements. For the association of performance of the financial distress prediction, he makes use of the clustering and BPN modeling. So that to get an early alarm. From the results of the method he comes to know four major critical attributes. The 1 st is that as more as we are using the factor analysis our result for clustering and BPN will be less accurate. 2nd is that that as soon as we get close to the actual financial distress, we will catch more precise outcome. 3rd is BPN has lower average rate of type ii errors as compare to the clustering model. In 4th the last stage the BPN provides a better and efficient prediction as that of the DM clustering approach [38]. In this paper [48] the author is dealing with different application of the data mining and then selects the best method among them. Firstly he finds out the hidden pattern using different data mining approaches. Then according to their results he Kept based on Back propagation neural network, the result of which is providing improved security as compare to the rest of them [48]. 
Table 2.1. Several Related Studies that Deal with Neural Network and Data Mining for using in Different Applications

\begin{tabular}{|c|c|c|c|c|}
\hline Ref. & Author name & Title of paper & Methods & $\begin{array}{c}\text { Feed } \\
\text { Forward }\end{array}$ \\
\hline$[1]$ & Priyanka Gaur & Neural networks in data mining & $\begin{array}{l}\text { Classification, clustering, feature } \\
\text { mining, Prediction and pattern } \\
\text { recognition. }\end{array}$ & $\sqrt{ }$ \\
\hline$[3]$ & Aleem Ali & A concise artificial neural network in data mining & $\begin{array}{c}\text { Statistical Method, Production rule IF } \\
\text { - THEN, Decision Tree, Genetic } \\
\text { Algorithms, Artificial Neural } \\
\text { Network. } \\
\end{array}$ & $\sqrt{ }$ \\
\hline [6] & $\begin{array}{l}\text { Sonal kadu, sheetal } \\
\text { Dhande }\end{array}$ & Effective Data Mining Through Neural Network & Neural network method & $\sqrt{ }$ \\
\hline [7] & Xianjun Ni & $\begin{array}{l}\text { Research of Data Mining Based on Neural } \\
\text { Network: }\end{array}$ & Neural network method & $\sqrt{ }$ \\
\hline [11] & Paulo Cortez & $\begin{array}{l}\text { Data mining with neural network and support } \\
\text { vector machines using the } \mathrm{r} / \mathrm{rminer} \text { tool }\end{array}$ & $\mathrm{DM}$ & $\mathrm{x}$ \\
\hline$[12]$ & $\begin{array}{l}\text { MstKamrunnahar } \\
\text { Mirna Urquidi- } \\
\text { Macdonald }\end{array}$ & $\begin{array}{l}\text { Prediction of corrosion behavior using neural } \\
\text { network as a data mining tool }\end{array}$ & Back propagation, & $\mathrm{x}$ \\
\hline$[13]$ & Paulo Certez & $\begin{array}{l}\text { Data mining with neural network and support } \\
\text { machine using the r/miner tool }\end{array}$ & $\mathrm{DM}$ & $\mathrm{x}$ \\
\hline$[14]$ & $\begin{array}{c}\text { Eduardo } \\
\text { Ogasawara, } \\
\text { Leonardo Murta, } \\
\text { Geraldo Zimbrao, } \\
\text { Marta Mattoso. }\end{array}$ & $\begin{array}{c}\text { Neural network Cartridge for Data Mining on } \\
\text { Time Series: }\end{array}$ & $\begin{array}{l}\text { Min-Max, Z-Score, Decimal Scaling } \\
\text { Normalization. }\end{array}$ & $\sqrt{ }$ \\
\hline$[15]$ & $\begin{array}{l}\text { Yakov Frayman, } \\
\text { Lipo Wang }\end{array}$ & $\begin{array}{l}\text { Data Mining Using Dynamic Constructed } \\
\text { Recurrent Fuzzy Neural Network: }\end{array}$ & $\begin{array}{l}\text { Symbolic decision tree, feed forward } \\
\text { neural network. }\end{array}$ & $\sqrt{ }$ \\
\hline$[16]$ & $\begin{array}{l}\text { Robert H.kewley, } \\
\text { Mark J.Embrechts, } \\
\text { Member, Curt } \\
\text { Breneman }\end{array}$ & $\begin{array}{l}\text { Data Strip mining for the virtual Design of } \\
\text { pharmaceuticals with neural networks }\end{array}$ & $\begin{array}{l}\text { Data strip Mining Methodology, } \\
\text { Model cross validation }\end{array}$ & $\sqrt{ }$ \\
\hline [17] & $\begin{array}{l}\text { Aine P Hearty and } \\
\text { Michael J Gibney }\end{array}$ & $\begin{array}{c}\text { Analysis of Meal Patterns with the use of } \\
\text { supervised data mining techniques Artificial } \\
\text { neural network and decision tree }\end{array}$ & $\begin{array}{c}\text { Artificial neural Network and } \\
\text { Decision Trees. }\end{array}$ & $\sqrt{ }$ \\
\hline$[18]$ & $\begin{array}{l}\text { Renpu Li, Zheng-ou } \\
\text { Wang }\end{array}$ & $\begin{array}{l}\text { Mining Classification rules using rough sets and } \\
\text { neural network }\end{array}$ & Rough set method & $\sqrt{ }$ \\
\hline [19] & $\begin{array}{l}\text { P.K. Dash, Maya } \\
\text { Nayak, } \\
\text { M.R.Senapati, } \\
\text { I.W.C.Lee }\end{array}$ & $\begin{array}{c}\text { Mining for similarities in time series data using } \\
\text { wavelet-based feature Vectors and neural } \\
\text { networks: }\end{array}$ & Wavelet- based method & $\sqrt{ }$ \\
\hline$[20]$ & $\begin{array}{l}\text { Francisco Palacios, } \\
\text { Xiaoou Li, Luis E. } \\
\text { Rocha }\end{array}$ & Data Mining based on CMAC Neural Networks: & & \\
\hline$[22]$ & $\begin{array}{l}\text { Xianyi Qian, } \\
\text { Xianjun Wang }\end{array}$ & $\begin{array}{c}\text { A New Study of DSS Based on Neural Network } \\
\text { and Data Mining }\end{array}$ & Double directions reasoning method & $\sqrt{ }$ \\
\hline [26] & $\begin{array}{c}\text { R.Bruce, } \\
\text { T.langsdorf, } \\
\text { M.hepp, frankfur A. } \\
\text { M }\end{array}$ & Neural data mining for credit card detection & & \\
\hline$[27]$ & $\begin{array}{c}\text { Hongjun Lu, } \\
\text { Rudysetionohuanliu }\end{array}$ & Effective data mining using neural network & Network Pruning Process & $\mathrm{x}$ \\
\hline$[32]$ & $\begin{array}{l}\text { James Malone, } \\
\text { Kenneth McGarry, } \\
\text { SafanWermter,Chri } \\
\text { sBuwerman }\end{array}$ & $\begin{array}{l}\text { Data mining using rule extraction from kohhnen } \\
\text { SOM }\end{array}$ & $\begin{array}{c}\text { Combination of SOM and color } \\
\text { mapping }\end{array}$ & $\sqrt{ }$ \\
\hline
\end{tabular}




\begin{tabular}{|c|c|c|c|c|}
\hline [38] & $\begin{array}{c}\text { Wei-Sen, Yin-kuan } \\
\text { Du }\end{array}$ & $\begin{array}{c}\text { Using neural networks and data mining } \\
\text { techniques for the financial distress prediction } \\
\text { model }\end{array}$ & Rules and statistical calculation & $\sqrt{ }$ \\
\hline [48] & $\begin{array}{c}\text { L. Wang and T. Z. } \\
\text { Sui }\end{array}$ & $\begin{array}{c}\text { Application of Data Mining Technology Based } \\
\text { on } \\
\text { Neural Network in the Engineering }\end{array}$ & Engineering & $\mathrm{x}$ \\
\hline
\end{tabular}

\section{Table 2.2. Related Algorithms that Deal with Neural Network and Data Mining for using in Different Applications}

\begin{tabular}{|c|c|c|c|c|}
\hline Ref. & Algorithm & Helping Algorithm & Data preparation & Rules extracting \\
\hline$[1]$ & $\mathrm{x}$ & $\mathrm{x}$ & $\sqrt{1}$ & $\sqrt{ }$ \\
\hline [3] & Competitive learning algorithm & $\begin{array}{l}\text { K-Mean clustering, MAFIA } \\
\text { algorithm }\end{array}$ & $\mathrm{x}$ & $\mathrm{x}$ \\
\hline$[6]$ & Back Propagation Algorithm & $\mathrm{x}$ & $\mathrm{x}$ & $\mathrm{x}$ \\
\hline [7] & $\mathrm{x}$ & $\mathrm{x}$ & $\sqrt{ }$ & $\sqrt{ }$ \\
\hline [11] & BFGS & $\mathrm{x}$ & $\mathrm{x}$ & $\mathrm{x}$ \\
\hline [12] & Levenberg-Marquardt. & $\mathrm{x}$ & $\mathrm{x}$ & $\mathrm{x}$ \\
\hline [13] & BFGS & $\mathrm{x}$ & $\mathrm{x}$ & $\mathrm{x}$ \\
\hline [14] & Genetic & & Graphs and charts & \\
\hline [15] & $\begin{array}{l}\text { Learning Algorithm, Decision tree algorithm } \\
\text { C4.5 and C4.5rules. }\end{array}$ & Decision tree & & \\
\hline [16] & Genetic & & Graph & \\
\hline [17] & $\mathrm{C} 5$ & Decision tree & Graphs and charts & \\
\hline [18] & NNFS, RSAR,RSRG, The General & & Tables & \\
\hline [19] & $\begin{array}{l}\text { Gradient descent Algorithm, RLS ( Recursive } \\
\text { least-Square), LMS( Least mean square) }\end{array}$ & Recursive least-Square & Graphs and tables & \\
\hline [20] & CMAC & & Graphs & \\
\hline [22] & $\mathrm{X}$ & & Flow charts & \\
\hline [26] & $\begin{array}{l}\text { Mining the symbolic data, mining the analog } \\
\text { data, combining symbolic and analog data }\end{array}$ & $\mathrm{x}$ & Tables and graphs & $\mathrm{x}$ \\
\hline [27] & $\begin{array}{l}\text { Finding symbolic classification using neural } \\
\text { network }\end{array}$ & Advanced & $\mathrm{x}$ & $\mathrm{x}$ \\
\hline [32] & Self-organizing maps & Unsupervised & $\begin{array}{l}\text { Clustering of } \\
\text { different data }\end{array}$ & $\sqrt{ }$ \\
\hline [38] & $\begin{array}{l}\text { Artificial neural network and data mining } \\
\text { techniques }\end{array}$ & Supervised/unsupervised & Charts and graphs & $\mathrm{x}$ \\
\hline [48] & Back Propagation neural network algorithm & $\mathrm{x}$ & Tables and graphs & $\mathrm{x}$ \\
\hline
\end{tabular}

\section{Table 2.3. Advantages, Techniques, Datasets, Model and Tools of the} Different Proposed Studies

\begin{tabular}{|c|c|c|c|c|c|}
\hline Ref. & $\begin{array}{c}\text { Rules } \\
\text { Assessment }\end{array}$ & Advantage & Technique & Data set & Model \\
\hline$[1]$ & $\sqrt{ }$ & $\begin{array}{c}\text { Good robustness, Self- } \\
\text { organizing adaptive, Parallel } \\
\text { Processing, Fault Tolerance }\end{array}$ & $\mathrm{x}$ & $\mathrm{x}$ & $\begin{array}{c}\text { Classification, } \\
\text { predictive, clustering } \\
\text { and association rules }\end{array}$ \\
\hline$[3]$ & $\mathrm{x}$ & $\begin{array}{c}\text { High Accuracy, Noise } \\
\text { tolerance, Erase of } \\
\text { maintenance, Neural } \\
\text { Network. }\end{array}$ & $\mathrm{x}$ & $\mathrm{x}$ & $\mathrm{x}$ \\
\hline$[6]$ & $\mathrm{x}$ & $\begin{array}{c}\text { Fault Tolerance, Self- } \\
\text { organizing adaptive, Parallel } \\
\text { Processing, Good }\end{array}$ & $\mathrm{x}$ & $\mathrm{x}$ & $\mathrm{x}$ \\
\hline
\end{tabular}




\begin{tabular}{|c|c|c|c|c|c|c|}
\hline & & robustness, & & & & \\
\hline$[7]$ & $\sqrt{ }$ & $\begin{array}{l}\text { Parallel Processing, Fault } \\
\text { Tolerance, Good robustness, } \\
\text { Self-organizing adaptive, }\end{array}$ & $\begin{array}{c}\text { Effective } \\
\text { Combination of } \\
\text { N.Network and } \\
\text { DM technology }\end{array}$ & $\mathrm{x}$ & $\mathrm{x}$ & $\begin{array}{c}\text { Neural } \\
\text { network tool }\end{array}$ \\
\hline [11] & $\mathrm{x}$ & $\mathrm{x}$ & $\mathrm{x}$ & $\mathrm{x}$ & NN and SVM & $\begin{array}{c}\text { CRISP-DM, } \\
\text { R }\end{array}$ \\
\hline$[12]$ & $\mathrm{x}$ & $\mathrm{x}$ & $\begin{array}{c}\text { Supervised } \\
\text { learning technique }\end{array}$ & $\mathrm{x}$ & $\mathrm{NN}$ & Neural-ware \\
\hline [13] & $\mathrm{x}$ & $\mathrm{x}$ & $\mathrm{x}$ & $\mathrm{x}$ & NN and SVM & $\begin{array}{l}\text { r/miner and } \\
\text { CRISP-DM }\end{array}$ \\
\hline [14] & $\mathrm{x}$ & $\mathrm{x}$ & Neural Network & NSIFCS & $\begin{array}{c}\text { Linear Model ( AR, } \\
\text { ARMA) and nonlinear ( } \\
\mathrm{NN})\end{array}$ & Weka \\
\hline$[15]$ & $\sqrt{ }$ & $\begin{array}{l}\text { By using fuzzy logic we can } \\
\text { express knowledge in such a } \\
\text { way which is natural for the } \\
\text { people to understand. } \\
\text { It increase the speedup of } \\
\text { convergence of the network }\end{array}$ & $\begin{array}{l}\text { Fuzzy Neural } \\
\text { Network }\end{array}$ & & $\begin{array}{l}\text { Symbolic and Neural } \\
\text { model }\end{array}$ & $\mathrm{x}$ \\
\hline [16] & $\sqrt{ }$ & $\begin{array}{l}\text { It removes the confusion } \\
\text { among analysis on the } \\
\text { training set and validation so } \\
\text { that it is not precise for } \\
\text { specific model building } \\
\text { paradigm. }\end{array}$ & $\mathrm{x}$ & & Neural network model & \\
\hline [17] & $\mathrm{x}$ & & $\begin{array}{l}\text { Supervised Data } \\
\text { Mining technique. }\end{array}$ & & ANN & $\begin{array}{c}\text { SPSS } \\
\text { Clementine } \\
\text { Version } 9.0\end{array}$ \\
\hline [18] & $\mathrm{x}$ & $\begin{array}{c}\text { They don't need any } \\
\text { additional information about } \\
\text { data like probability in } \\
\text { statistic }\end{array}$ & & MONK3 & $\mathrm{NN}$ & \\
\hline [19] & $\mathrm{x}$ & S- Transform & $\begin{array}{l}\text { Fuzzy c-mean } \\
\text { Clustering }\end{array}$ & & & DWT \\
\hline$[20]$ & $\mathrm{x}$ & & Hashing & $\sqrt{ }$ & CMAC, MLP and C4.5 & \\
\hline$[22]$ & $\mathrm{x}$ & & $\begin{array}{l}\text { Solutions module } \\
\text { and data mining } \\
\text { module }\end{array}$ & & $\begin{array}{c}\text { language system (LS), } \\
\text { problem process system } \\
\text { (PPS) and knowledge } \\
\text { system. } \\
(\mathrm{KS})\end{array}$ & \\
\hline [26] & $\sqrt{ }$ & $\begin{array}{l}\text { High correctness and high } \\
\text { confidence }\end{array}$ & & $\mathrm{x}$ & Decisions & $\begin{array}{l}\text { A Neural } \\
\text { network } \\
\text { algorithm }\end{array}$ \\
\hline [27] & $\sqrt{ }$ & $\begin{array}{c}\text { To reduce training time of } \\
\text { neural network }\end{array}$ & Rules & $\mathrm{x}$ & $\begin{array}{l}\text { Extracting rules from } \\
\text { trained neural network }\end{array}$ & $\begin{array}{c}\text { Classification } \\
\text { using neural } \\
\text { network }\end{array}$ \\
\hline$[32]$ & $\sqrt{ }$ & $\begin{array}{l}\text { vital accuracy of clustering } \\
\text { route execute by SOM }\end{array}$ & Rules based & Real data & Extracting rules & $\mathrm{x}$ \\
\hline$[38]$ & $\mathrm{x}$ & $\begin{array}{c}\text { Using existing techniques to } \\
\text { deal with more financial } \\
\text { datasets }\end{array}$ & $\begin{array}{c}\text { Financial distress } \\
\text { environment }\end{array}$ & $\begin{array}{c}\text { Supervised } \\
\text { /unsupervised }\end{array}$ & $\begin{array}{l}\text { BPN, clustering and } \\
\text { classification }\end{array}$ & $\begin{array}{l}\text { ANN and } \\
\text { data mining }\end{array}$ \\
\hline$[48]$ & $\mathrm{x}$ & $\mathrm{x}$ & Matlab & $\begin{array}{l}\text { Rules and } \\
\text { decisions }\end{array}$ & $\mathrm{x}$ & $\begin{array}{c}\text { Artificial } \\
\text { neural } \\
\text { network }\end{array}$ \\
\hline
\end{tabular}

\section{Data Mining for Medical Diagnosis}

This paper explains [2] that a huge amount of medical data is available but there is a lack of data analysis tool to extract useful knowledge from it. Unfortunately all doctors are not expert in all field of medical. Clinical results are often ready base on doctor's awareness and experience rather than on the knowledge masked in the database [2]. Data mining have the ability to produce a knowledge-rich situation which can aid to improve 
the worth of clinical decision, due to this reason automatic medical diagnoses system is very useful by fetching all of them together. Genetic Algorithm is used to reduce the actual size of data which is enough for heart disease [2]. For experiments it use Weka 3.6.0 tool. The inconsistency was resolved for simplicity. Decision tree fail the two other techniques. It gives $99.2 \%$ accuracy. Association rule shows the favorable technique to increase heart diseases estimate [2].The second assumption is that the precision of the Decision Tree and Bayesian Classification further expand after applying Genetic algorithm to decrease the finest subset of attribute sufficient for heart disease prediction [2].

It has been observed that the healthcare industry is generally "information rich", but unfortunately not all the data are mined which is required for discovering hidden patterns $\&$ effective decision making [4]. For the extraction of knowledge it need powerful data analysis tool [4]. A major challenge facing healthcare industry is quality of service. Quality of service implies diagnosing disease correctly \& provides effective treatments to patients. Poor diagnosis can lead to disastrous consequences which are unacceptable. Heart diseases stored professional significant amounts of patient's data [4]. It is necessary to scrutinize this data set to extract valuable knowledge. Knowledge of risky factors which are linked with the heart disease helps the care professional to identify the patients which have high risk of heart diseases [4]. They apply different technique of data mining to know which one will give accurate result. Statistical analysis has shown that the causes of heart disease are: Smoking habit, blood pressure, lack of physical activity etc. Several data mining technique are use in diagnose of heart disease which are Decision Tree, Kernel density, Naïve Bayes, Neural Network [4]. In this paper [10] the author explains that the leading cause of perinatal morbidity and mortality is preterm birth. The main theme of this study is to clear the risk factors of preterm with decision tree and neural network using data mining. The data mining is used to explore the potential factor of huge amount of data but still the preterm birth is still unclear. The preterm risks factor is related to smoking, drinking and work is also displayed in the result [10]. One of the important proposals is that in the risk of preterm birth, men are also the contributing factor. It is necessary for the prospective fathers to adopt decent life style habit, so to keep safe his children from being born preterm [10].

The network interference is a branch of systems biology where in collaborations among the contender of the system are connected to each other logically signifying the behavior of the system [8]. Estrogen receptor status is a vital concern in the prognosis and management of breast cancer patients [8]. The computational approaches are : Data sets used for analysis, phase 1 identification of biomarker probes associated with Estrogen Receptor status, phase 2 Artificial Neural Network based Network inference and visualization. In result we have probe selection and network inference. For the grouping of data mining and network inference the key genes seem to be TONDU GATA3, CDH3 F0XA1 and SOX11 are called transcription factor [8].The combine tactic of Artificial neural network based network inference and Artificial neural network base data mining we have recognized 6 genes that associate with ER system in breast cancer. Only 4 are strongly associated with ER status [8]. The theme of the paper [39] is to collect information about breast cancer disease. This is known as a serious cancer disease throughout the globe. The goal of this author is to divide woman in two categories i.e the woman who has broad confirmations of having breast cancer are grouped into malignant and having no breast disease are grouped into benign. So the author tried to propose such a hybrid breast cancer diagnose system by joining together artificial neural network and MRAS [39]. This method is then combines with the BPN. Now in this case this model has high classification accuracy. Form the result of the hybrid and the combination of hybrid and BPN it is clear that Hybrid and BPN provide lots of accuracy but the main advantage of hybrid system is that it can save lots of implementation time which results in making shorten the time for on time decisions [39]. 
In this article [41] the author focuses on one of major issue in neural network. Neural network have been used for regression and classification method in past. The interpretations of their internal representation were very difficult. Now a day, it is clear that for the extraction of the understandable representation from trained neural network algorithm can be derived. The purpose of which is to use for data mining applications. The work mentioned in this paper delivers a generalized procedure, which can be used for the problems in bioinformatics [41]. The results are really impressive but the problem is that of producing a large amount of data. Combination of algorithm with the neural network for the purpose of extracting of information from the trained neural network is the best solution, which produces high accurate data along with that produces knowledge discovery. The usage of these methods leads to acceptance and high confidence [41]. In this whole paper [44] the author is curious about getting high blood pressure data from a hospital data base. He is using back propagation algorithm in a multi-layered neural network. In building decision the results offered are very attractive [44]. With the help of artificial intelligence approaches the hypothesis or activities of data is shown along with that formerly unknown data is exposed. This is all due to neural networks that the author is able to model irregular data and complex structure along with that various other issues [44]. The author focuses on the diagnosis and fault forecast methods of stream turbine which is totally based on the genetic and neural network [49]. For fault diagnosis in stream turbine and in data mining the genetic and neural network algorithm were introduces. By comparing the novel approach to the traditional approach it is quite clear that has better performance and simple to design [49]. With the help of proposed algorithm sharing turbine fault diagnosis and rules extraction which is based on genetic and neural network algorithm are producing good results. The given system provide a good output with better confidence along with that it has strong ability of fault tolerant [49].

Table 3.1. Several Related Studies that Deal with Neural Network and Data Mining for using in Different Applications in Medical Diagnosis

\begin{tabular}{|c|c|c|c|c|}
\hline Ref. & Author name & Title of paper & Methods & $\begin{array}{c}\text { Feed } \\
\text { Forward }\end{array}$ \\
\hline$[2]$ & $\begin{array}{l}\text { Jyoti Soni ,Ujma Ansari, Dipesh } \\
\text { Sharma, SunitaSoni. }\end{array}$ & $\begin{array}{l}\text { Predictive data mining for medical diagnosis: } \\
\text { an overview of heart disease prediction }\end{array}$ & Rule Pruning & $\sqrt{ }$ \\
\hline$[4]$ & $\begin{array}{c}\text { Mai Shouman, Tim Turner, Rob } \\
\text { Stocker. }\end{array}$ & $\begin{array}{l}\text { Using data mining techniques in heart disease } \\
\text { diagnosis and treatment }\end{array}$ & $\mathrm{x}$ & $\mathrm{x}$ \\
\hline$[10]$ & $\begin{array}{l}\text { Hisang-Yang Chen, Chao-Hua } \\
\text { Chuang, Yao-Jung Yang, Tung- } \\
\text { Pi Wu. }\end{array}$ & $\begin{array}{c}\text { Exploration the risk factors of preterm birth } \\
\text { using data mining }\end{array}$ & $\begin{array}{l}\text { Neural Network and Decision } \\
\text { Tree C5.0, ID3. }\end{array}$ & $\mathrm{x}$ \\
\hline$[8]$ & $\begin{array}{l}\text { Gopal K Dhondalay, Christophe } \\
\text { Lemetre and Graham R Ball. }\end{array}$ & $\begin{array}{l}\text { Modeling Estrogen Receptor pathways in } \\
\text { breast cancer using an Artificial Neural } \\
\text { Network Based inference Approach }\end{array}$ & $\begin{array}{l}\text { Dataset used for analysis, Phase } 1 \\
\text { identification of biomarker probes } \\
\text { associated with Estrogen Receptor } \\
\text { status, Phase } 2 \text { ANN based on } \\
\text { inference, Visualization }\end{array}$ & $\sqrt{ }$ \\
\hline [39] & $\begin{array}{l}\text { Shienu-Ming Chou, Tian - } \\
\text { Shyug Lee, YuehjenE.Shao, I- } \\
\text { Fei Chen }\end{array}$ & $\begin{array}{l}\text { Mining the breast cancer pattern using } \\
\text { artificial neural network and multivariate } \\
\text { adaptive regression splines }\end{array}$ & Rules and decisions & $\sqrt{ }$ \\
\hline$[41]$ & $\begin{array}{l}\text { Antoney Browne, Brain D. } \\
\text { Hudson, David C. Whitley, } \\
\text { Martyn G. Ford, Philip Picton }\end{array}$ & $\begin{array}{c}\text { Biological data mining using neural networks } \\
\text { implementation and application of a flexible } \\
\text { decision tree extraction algorithm to genomic } \\
\text { problem domains }\end{array}$ & Transportation research & $\mathrm{x}$ \\
\hline$[44]$ & $\begin{array}{l}\text { MbuyiMukendiKafundaKatatayi } \\
\text { Pierre, MbuyiBadibangaSreve, } \\
\text { MbuyiMukendi Didier }\end{array}$ & $\begin{array}{l}\text { Extraction knowledge from high pressure } \\
\text { data patients }\end{array}$ & $\begin{array}{c}\text { Extraction of knowledge form } \\
\text { data base with high blood } \\
\text { pressure }\end{array}$ & $\mathrm{x}$ \\
\hline [49] & Qingling & $\begin{array}{c}\text { A novel approach of diagnoses stream turbine } \\
\text { based on neural network and genetic } \\
\text { algorithm }\end{array}$ & Stream turbine & $\mathrm{x}$ \\
\hline
\end{tabular}




\section{Table 3.2. Related Algorithms that Deal with Neural Network and Data Mining for using in Different Applications in Medical Diagnosis}

\begin{tabular}{|c|c|c|c|c|}
\hline Ref. & Algorithm & Helping Algorithm & $\begin{array}{c}\text { Data } \\
\text { Preparation }\end{array}$ & $\begin{array}{l}\text { Rules } \\
\text { Extracting }\end{array}$ \\
\hline$[2]$ & $\begin{array}{l}\text { Multi-layer perceptron Neural network } \\
\text { (MLPNN), Genetic Algorithm }\end{array}$ & K-Mean clustering, MAFIA algorithm & $\mathrm{x}$ & $\mathrm{x}$ \\
\hline [4] & $\mathrm{x}$ & $\mathrm{x}$ & $\mathrm{x}$ & $\mathrm{x}$ \\
\hline$[10]$ & C 5.0 & $\mathrm{x}$ & $\mathrm{x}$ & $\mathrm{x}$ \\
\hline$[8]$ & $\mathrm{x}$ & $\mathrm{x}$ & $\mathrm{x}$ & $\mathrm{x}$ \\
\hline [39] & $\begin{array}{l}\text { Data mining technique with multivariate } \\
\text { adoptive regression splines(MARS) }\end{array}$ & $\mathrm{x}$ & Charts and graphs & $\sqrt{ }$ \\
\hline [41] & Statistical and computational thoughts. & Traditional vs. new techniques & Tables & $\mathrm{x}$ \\
\hline [44] & Multi-layer neural network & $\mathrm{x}$ & Tables & $\mathrm{x}$ \\
\hline [49] & $\begin{array}{l}\text { Novel approach based on neural network } \\
\text { and genetic algorithm }\end{array}$ & Traditional vs novel approach & Tables & $\mathrm{x}$ \\
\hline
\end{tabular}

Table 3.3. Advantages, Techniques, Datasets, Model and Tools of the Different Studies in Medical Diagnosis

\begin{tabular}{|c|c|c|c|c|c|c|}
\hline Ref. & $\begin{array}{c}\text { Rules } \\
\text { Assessment }\end{array}$ & Advantage & Techniques & Data set & Model & Tools \\
\hline$[2]$ & $\sqrt{ }$ & $\mathrm{x}$ & $\begin{array}{c}\text { Naïve Bayes, Decision } \\
\text { Tree, Neural Network, } \\
\text { Rough set Theory }\end{array}$ & $\sqrt{ }$ & $\mathrm{x}$ & Tanagra, Weka 3.6.0 \\
\hline [4] & $\mathrm{x}$ & $\begin{array}{c}\text { Uses of DM techniques } \\
\text { identify a suitable } \\
\text { treatment for Heart } \\
\text { disease. }\end{array}$ & $\begin{array}{l}\text { Single and Hybrid, } \\
\text { Naïve Bayes, Decision } \\
\text { Tree, Neural Network }\end{array}$ & $\begin{array}{l}\text { Cleveland Heart } \\
\text { Disease } \\
\text { Dataset(CHDD) }\end{array}$ & $\mathrm{x}$ & $\mathrm{x}$ \\
\hline$[10]$ & $\mathrm{x}$ & $\mathrm{x}$ & $\mathrm{x}$ & $\mathrm{x}$ & $\mathrm{x}$ & Clementine 10.0 \\
\hline [8] & $\sqrt{ }$ & $\begin{array}{c}\text { Back Propagation } \\
\text { Algorithm }\end{array}$ & $\mathrm{x}$ & $\mathrm{x}$ & $\mathrm{x}$ & $\mathrm{x}$ \\
\hline [39] & $\mathrm{x}$ & $\begin{array}{c}\text { Collecting more } \\
\text { important variable that } \\
\text { increase classification } \\
\text { accuracy }\end{array}$ & Rules and decisions & $\mathrm{x}$ & BPN & $\begin{array}{l}\text { Artificial intelligence } \\
\text { and data mining } \\
\text { techniques }\end{array}$ \\
\hline$[41]$ & & $\mathrm{x}$ & Decision tree & Decision tree & $\begin{array}{c}\text { Trepan } \\
\text { Algorithm }\end{array}$ & $\begin{array}{c}\text { Statistical predictions } \\
\text { and artificial } \\
\text { intelligence }\end{array}$ \\
\hline [44] & $\mathrm{x}$ & $\mathrm{x}$ & Rules & Supervised & BPN & $\begin{array}{c}\text { Neural network using } \\
\text { supervised learning }\end{array}$ \\
\hline [49] & $\mathrm{x}$ & $\mathrm{x}$ & $\mathrm{x}$ & Rules & $\mathrm{x}$ & $\begin{array}{c}\text { Artificial neural } \\
\text { network with genetic } \\
\text { algorithm }\end{array}$ \\
\hline
\end{tabular}

\section{Classification and Neural Network}

In this paper [21] the author tells us that by using the auto-configuring RBF network we have shown that symbolic data can be classified with better generalization. In the first step we have shown the symbolic representation in binary form and then for obtaining the clustering form binaries' symbolic data we used simple hamming distance measure [21]. Now in second part we have pick the in each cluster we have a specific percentage of significant data samples, and then we use it to train the Adaptive Auto-Configuring neural network. Several researchers have explored the analysis of symbolic data; they treat it with different mathematical framework and submit good result. The technique which is available didn't provide us good generalization for test sample [21]. In this paper the author uses the UCI machine learning repository and he has taken the benchmark dataset from it [21], and with respect to Medio's he proposed to find the clusters and the sample has been trained by using Fuzzy redial basis function neural network which report very 
good result. The disadvantage of the proposed scheme is network fixed architecture [21]. This paper [29] describes the implementation of artificial neural network in field of solid ducted rocket test. Furthermore it tells that ANN is combined with RBF (redial basis function) to recover the abnormal data [29]. The ANN model is based on three layered architecture. Which takes data on input node then transform it to middle layer called hidden node then it moves toward the output node [29]. When data moves toward the hidden node then it applies data mining techniques on large data and finds the correlation between different data. This algorithm detects and recovers the irregular parameters rapidly and efficiently [29]. In this paper [33] the author describes a novel approach for Expert system application. He made use of an algorithm called MTS (MahalanobisTaguchi system) ANN(artificial neural network) in expert system. He implemented this algorithm in dynamic environment [33]. The experimental outcomes of this algorithm proved that this algorithm is vastly valid in pattern recognition and is computationally efficient in addition to the ANN algorithm, is a straightforward and resourceful system for assembling a dynamic structure [33]. From this it can be accomplished that MTS-ANN algorithm can be effectively useful to dynamic environment for data-mining troubles [33]. In this given research the author is curious in the field of transportation and wants to apply different data mining techniques to find out dissimilarities, similarities. He is cautious to know similarities and dissimilarities between two different schools of thoughts. He furthermore made experiments on different technique using complex structure. And find out that along with the advantage of the complex modeling tools it has limitation as well. This is a big hurdle in the way of finding similarities and dissimilarities. From this he simply concluded that instead of using complex modeling technique the goal of analyzing is much important. Because there are always assumption in all modeling approaches. So with the help of simpler model give us a good result just like complex one

In this article [42] the author is dealing with the prediction of gully initiation. In past predicting gully initiation was prepared with the help of GIF scheme with knowledge base expert system, physical based system or statistical procedures. But while applying these procedures validity and reliability are big issues. For the identification and risk of gully initiation a procedure known as Data mining which is based on decision trees is applied. In this article the comparison of DM technique is shown with many other procedures like expert system and topographic threshold method (TT) [42]. The results show that DM technique provides more accurate data than that of the other methods. So it is obvious that for the study of the erroneous procedure and gully initiation a valuable technique is DM technique [42] in this article [45] the author focuses on one of major issue in neural network. Neural network have been used for regression and classification method in past. And the interpretation of their internal representation was very difficult. Now a day, it is clear that for the extraction of the understandable representation from trained neural network algorithm can be derived. The purpose of which is to use for data mining applications [45]. The work mentioned in this paper delivers a generalized procedure, which can be used for the problems in bioinformatics. The results are really impressive but the problem is that of producing a large amount of data. Combination of algorithm with the neural network for the purpose of extracting of information from the trained neural network is the best solution, which produces high accurate data along with that produces knowledge discovery. The usage of these methods leads to acceptance and high confidence [45]. In data mining classification is a key subject to be focused [47]. But dealing with incomplete survey then classification is an innovative subject. Traditional neural network and other technique did not focus on the incomplete survey. So the author presents a novel approach known as extension neural network approach to deal with the incomplete survey [47]. This proposed approach is dealing with the supervised data. After comparing the result of the planned approach with other approaches, it clearly shows that this approach has the benefit of high accuracy over other approaches [47]. 
Table 4.1. Several Related Studies that Deal with Neural Network and Data Mining for using in Different Applications

\begin{tabular}{|c|c|c|c|c|c|}
\hline Ref. & $\begin{array}{l}\text { Author } \\
\text { Name }\end{array}$ & Title of paper & Approach & $\begin{array}{l}\text { Real } \\
\text { Data }\end{array}$ & Model \\
\hline [21] & $\begin{array}{l}\text { TN Nagabhushan, } \\
\text { HanseokKo, Junbum } \\
\text { Park, S K Padma, Y } \\
\text { S Nijagunarya }\end{array}$ & $\begin{array}{c}\text { Classification of Symbolic Objects using } \\
\text { Adaptive Auto-Configuring RBF Neural } \\
\text { Networks }\end{array}$ & $\begin{array}{l}\text { Mean and } \\
\text { Mediod }\end{array}$ & $\sqrt{ }$ & \\
\hline [29] & $\begin{array}{l}\text { Qiangliu, futtingbao, } \\
\text { binggexia, xi'an P.R }\end{array}$ & $\begin{array}{l}\text { Data analysis and SDR test based on ANN } \\
\text { model }\end{array}$ & $\begin{array}{c}\text { Detect and } \\
\text { recover the } \\
\text { abnormal } \\
\text { parameter } \\
\text { effectively }\end{array}$ & & $\begin{array}{l}\text { k-mean clustering } \\
\text { algorithm }\end{array}$ \\
\hline [33] & $\begin{array}{l}\text { Ching-lien huang, } \\
\text { tsung-shin hsu, chih- } \\
\text { mingliu }\end{array}$ & $\begin{array}{l}\text { The MTS-ANN algorithm for data mining } \\
\text { in dynamic environments }\end{array}$ & $\begin{array}{c}\text { Pattern } \\
\text { recognition, } \\
\text { model } \\
\text { construction and } \\
\text { high confidence }\end{array}$ & $\sqrt{ }$ & $\begin{array}{l}\text { Linear correlation } \\
\text { discovering }(\mathrm{LCD})\end{array}$ \\
\hline [40] & $\begin{array}{l}\text { M.G Karlatis, E.I } \\
\text { Vlahogianni }\end{array}$ & $\begin{array}{c}\text { Statistical method vs neural networks in } \\
\text { transportation research, differences, } \\
\text { similarities and some insights }\end{array}$ & $\mathrm{x}$ & $\sqrt{ }$ & $\mathrm{x}$ \\
\hline [42] & $\begin{array}{c}\text { Tal Svoray, } \\
\text { EvgeniaMichailov, } \\
\text { Avraham Cohen, } \\
\text { LiorRokah and Arnon } \\
\text { Sturm }\end{array}$ & $\begin{array}{l}\text { Predicting gully initiation:Comparing data } \\
\text { mining techniques, analytical hierarchy } \\
\text { processes and the topographic }\end{array}$ & $\mathrm{x}$ & $\sqrt{ }$ & $\begin{array}{l}\text { Decision tree } \\
\text { algorithm, ANN, } \\
\text { TT,AHP }\end{array}$ \\
\hline$[45]$ & $\begin{array}{c}\text { Antoney Browne, } \\
\text { Brain D. Hudson, } \\
\text { David C. Whitley, } \\
\text { Martyn G. Ford, } \\
\text { Philip Picton } \\
\end{array}$ & $\begin{array}{l}\text { Implementation and application of a } \\
\text { flexible decision tree extraction algrothm } \\
\text { to genomi problem domain }\end{array}$ & $\mathrm{x}$ & $\sqrt{ }$ & Trepan Algorithm \\
\hline [47] & $\begin{array}{l}\text { Chao Lu, Xue- Wei } \\
\text { Li, Hong-Bo Pan }\end{array}$ & $\begin{array}{c}\text { Application of Extension Neural Network } \\
\text { for Classification with Incomplete } \\
\text { Survey Data }\end{array}$ & $\begin{array}{c}\text { develop an } \\
\text { unsupervised } \\
\text { learning } \\
\text { algorithm of the } \\
\text { proposed } \\
\text { extension neural } \\
\text { network, } \\
\end{array}$ & $\sqrt{ }$ & $\begin{array}{l}\text { Neural network and } \\
\text { classification }\end{array}$ \\
\hline
\end{tabular}

Table 4.2. Advantages, Techniques, Datasets, Model and Tools of the Different Studies

\begin{tabular}{|c|c|c|c|c|c|c|c|}
\hline Ref. & $\begin{array}{c}\text { Data } \\
\text { Representation }\end{array}$ & Algorithm & Techniques & Synthetic & Theorem & Data set & $\begin{array}{c}\text { Type of } \\
\text { symbolic data }\end{array}$ \\
\hline$[21]$ & $\begin{array}{c}\text { Binaries } \\
\text { representation }\end{array}$ & $\begin{array}{l}\text { agglomerative } \\
\text { clustering } \\
\text { algorithm , } \\
\text { adaptive RBF } \\
\text { algorithm }\end{array}$ & $\begin{array}{l}\text { Adaptive Auto- } \\
\text { configuring RBF } \\
\text { neural network }\end{array}$ & $\mathrm{x}$ & $\begin{array}{c}\text { Vapnik- } \\
\text { Chervonenkis } \\
\text { (VC) } \\
\text { Dimension }\end{array}$ & $\begin{array}{c}\text { soybean } \\
\text { bench mark }\end{array}$ & $\begin{array}{c}\text { Assertion, Hoard } \\
\text { and } \\
\text { Synthetic }\end{array}$ \\
\hline [29] & SDR test & $\begin{array}{l}\text { Radial basis } \\
\text { function }\end{array}$ & $\begin{array}{c}\text { Artificial neural } \\
\text { network }\end{array}$ & & & Test data & $\begin{array}{c}\text { ANN layered } \\
\text { based }\end{array}$ \\
\hline [33] & $\begin{array}{c}\text { Charts and } \\
\text { tables }\end{array}$ & MTS-ANN & $\begin{array}{c}\text { Statistical data, } \\
\text { charts }\end{array}$ & $\sqrt{ }$ & & Real data & $\begin{array}{c}\text { Rule } \\
\text { /statistical based }\end{array}$ \\
\hline [40] & Charts & $\begin{array}{c}\text { Statistical and } \\
\text { computational } \\
\text { thoughts. }\end{array}$ & $\begin{array}{l}\text { Transportation } \\
\text { research }\end{array}$ & & $\begin{array}{c}\text { Statistical } \\
\text { predictions } \\
\text { and artificial } \\
\text { intelligence }\end{array}$ & $\begin{array}{c}\text { Predictions } \\
\text { and previous } \\
\text { data }\end{array}$ & $\begin{array}{c}\text { Supervised } \\
\text { /unsupervised }\end{array}$ \\
\hline$[42]$ & $\begin{array}{l}\text { Graph, charts } \\
\text { and tables }\end{array}$ & $\begin{array}{c}\text { Data mining } \\
\text { procedure based } \\
\text { on decision trees }\end{array}$ & $\begin{array}{l}\text { Transportation } \\
\text { research }\end{array}$ & $\sqrt{ }$ & $\begin{array}{c}\text { Traditional vs } \\
\text { DM } \\
\text { techniques }\end{array}$ & Test data & $\begin{array}{c}\text { Rules and } \\
\text { statistical } \\
\text { analysis } \\
\end{array}$ \\
\hline [45] & Tables & $\begin{array}{c}\text { Statistical and } \\
\text { computational } \\
\text { thoughts. }\end{array}$ & $\begin{array}{l}\text { Genomic problem } \\
\text { domain }\end{array}$ & $\mathrm{x}$ & $\begin{array}{c}\text { Statistical } \\
\text { predictions } \\
\text { and artificial } \\
\text { intelligence }\end{array}$ & $\begin{array}{c}\text { Decision } \\
\text { Tree }\end{array}$ & $\mathrm{x}$ \\
\hline [47] & Graphs & $\begin{array}{c}\text { Extension neural } \\
\text { network based } \\
\text { on model of } \\
\text { clustering }\end{array}$ & $\begin{array}{l}\text { classification with } \\
\text { incomplete survey }\end{array}$ & $\mathrm{x}$ & $\begin{array}{l}\text { ANN and data } \\
\text { mining } \\
\text { technique }\end{array}$ & Supervised & Rules/Supervised \\
\hline
\end{tabular}




\section{Neural Network Approach and Data Envelopment Analysis}

This paper [5] describes association rules as one of the essential method of data mining. It shows some aspect of database that is not known before. Ranking the association rules is very important in market in decision creation and basket analysis [5]. For updating the rank table of association rules a new method has been proposed. In the market basket when new transactions are added then for refreshing the ranking table we apply the artificial neural network. By data envelopment analysis it prevents to repeat all the process of problem [5]. Minimum support and minimum confidence are the two factors of an association rule which determine the strength of a rule. DEA is a nonparametric method. It uses multiple input and output for the measurement of entity performance. In future work, for achieving this goal we could examine the instant base reasoning (case based reasoning) [5]. In this proposed paper [35] the author introduces a new neural approach known as ensemble recursive rule extraction. This approach is basically mining of rules from the ensemble neural network. In this approach we come to know that the proposed approach produces higher recognition accuracy as compared to the individual neural network, where the mined rules are more comprehensible. The proposed approach gives more rules than the previous approaches [35]. For neural data analysis this proposed approach promises a new approach. So it is clear that in future this approach will be used to escalate the opportunities to use data mining for the purpose of high data recognition [35]. Dealing with the predictions of the winner of the college football team is a challenging and interesting task. The previous studies show us that all the previous predictions were failed because they were dealing with the ranking and force of the team [36]. Here the author has predicted a novel approach the author used three techniques (artificial neural network, support vector machine and decision trees) the purpose of using these technique is to create regression and classification kind of models so that to review different methodologies prediction ability [36]. This method proved that this approach is better way to present the future predictions and can provide a lot of accurate results than the previous predictions [36].

Table 5.1. Several Related Studies that Deal with Neural Network and Data Mining for using in Different Applications

\begin{tabular}{|c|c|c|c|c|}
\hline Ref. & Author name & Title of paper & Methods \\
\hline$[5]$ & $\begin{array}{c}\text { AliakbarNiknafs } \\
\text { and } \\
\text { soodabehparsa. }\end{array}$ & $\begin{array}{c}\text { A Neural Network Approach For Updating Ranked } \\
\text { Association Rules, Based On Data Envelopment } \\
\text { Analysis }\end{array}$ & Proposed Method \\
\hline$[35]$ & $\begin{array}{c}\text { Atsushi Hara, } \\
\text { Yoichi Hayashi }\end{array}$ & $\begin{array}{c}\text { New neural data analysis approach using ensemble } \\
\text { neural network rule extraction }\end{array}$ & $\begin{array}{c}\text { Getting of rules from ensemble } \\
\text { neural network }\end{array}$ \\
\hline$[36]$ & $\begin{array}{c}\text { DursunDelen, } \\
\text { Douglas } \\
\text { Cogdell, } \\
\text { NihatKasap }\end{array}$ & $\begin{array}{c}\text { A comparative analysis of data mining methods in } \\
\text { predicting NCAA bowl outcomes }\end{array}$ & $\begin{array}{c}\text { Predicting the outcomes of the } \\
\text { college football games }\end{array}$ \\
\hline
\end{tabular}

Table 5.2. Related Algorithms that Deal with Neural Network and Data Mining for using in Different Applications

\begin{tabular}{|c|c|c|c|c|}
\hline Ref. & Algorithm & Helping Algorithm & Data Preparation \\
\hline$[5]$ & Apriori & $\mathrm{x}$ & $\mathrm{x}$ & $\mathrm{x}$ \\
\hline$[35]$ & $\begin{array}{c}\text { Ensemble Recursive Rules } \\
\text { Extraction (E-Re-Rx) }\end{array}$ & $\mathrm{x}$ & $\mathrm{x}$ & Charts and graphs \\
\hline$[36]$ & CRISP-DM & $\mathrm{x}$ & $\mathrm{x}$ \\
\hline
\end{tabular}


Table 5.3. Advantages, Techniques, Datasets, Model and Tools of the Different Studies

\begin{tabular}{|c|c|c|c|c|c|c|c|}
\hline Ref. & $\begin{array}{c}\text { Rules } \\
\text { Assessment }\end{array}$ & Advantage & Techniques & Data set & Model & Tools & Real time \\
\hline$[5]$ & $\mathrm{x}$ & $\mathrm{x}$ & $\mathrm{x}$ & $\mathrm{x}$ & $\mathrm{x}$ & $\mathrm{x}$ & \\
\hline$[35]$ & $\mathrm{x}$ & $\begin{array}{c}\text { Using data mining } \\
\text { with high recognition } \\
\text { accuracy }\end{array}$ & Rules & $\begin{array}{c}\text { Learning data } \\
\text { sets }\end{array}$ & $\mathrm{x}$ & $\begin{array}{c}\text { Using neural } \\
\text { network rules }\end{array}$ & $\sqrt{ }$ \\
\hline$[36]$ & $\mathrm{x}$ & $\begin{array}{c}\text { Enrichment of variable } \\
\text { set, identifying and } \\
\text { including more input } \\
\text { variable }\end{array}$ & $\begin{array}{c}\text { Rules and } \\
\text { predictions }\end{array}$ & Real data & $\begin{array}{c}\text { Rules and } \\
\text { prediction } \\
\text { Artificial } \\
\text { neural } \\
\text { network } \\
\text { Support vector } \\
\text { machine }\end{array}$ & $\sqrt{ }$ \\
\hline
\end{tabular}

\section{Neural Network and Data Mining in Information Technology}

In this paper [23] the author tells us that the combination with neural network model and prediction model and CGNN model adopts the RBF neural network models and GM which plays a very vital role in analyzing user received data protection. In border range the grey system is applied which contain feature of nursing to decrease and increase well [23]. Nonlinear dynamic and self-adopt system is a kind of neural network method. To overcome the series of problem in application data mining and grey system theory can be waged for each other. The effect of analyzing data safety is good by the combination of neural network and grey system in order to defend data from attack. The CGNN model proves that it is more effective than simple model [23]. Mat lab is a tool which has being used for this. And the methods used were Training samples and least square method [23]. This paper [9] explains that with the increasing amount of data the value of data mining also increases. The study is undertaken to find the new ways to find information from news through internet and apply interest rate on the basis of this information, so we propose the Knowledge-Based News Miner (KBNMiner). It shows the knowledge of interest rate with CMs (Cognitive Maps) [9]. According to prior knowledge it retrieves and search information of NEWS on internet, and then this information were applied on the neural network model for the interest rate prediction. The perception of human being can be captured by a proper tool called CM, which was developed by Axelrod in 1976. The domain expert is usually employed by knowledge-based expert system [9]. The converting of the expert knowledge into knowledge base is the responsibility of knowledge engineer. The knowledge engineers have two or more domain map and extract the CMs [9]. He tries to make it one but the domain experts are not agreeing with this sometime. So for the obtaining more correct result we have to improve the algorithm of IR system and also need to refine the CMs [9]. This paper [30] tells us about the implementation of data mining approach in urban water system. In data mining approach further they implement neural network approach. Furthermore in detail they introduced self-organizing maps approach in neural network. The job of which is to collect DNA based molecular techniques and to analyze environmental samples [30]. in microbiology to group different samples. Comparison of many T-RFLP (terminal restriction fragment length polymorphism) profiles to discover collective and single components of microbiology community. T-Align software is used for grouping these things. The main benefit of this approach is the capability to present the data in a visual way that offers effortless visualization and understanding of multi-dimensional and complex data sets [30].

The paper [31] describes the unsupervised visual data mining using SOM and a data driven color mapping. The author uses two different algorithms for finding the solution of this problem. The 1st method that the author used is SOM (self-organizing map). This algorithm yields two dimensional and irregular representations of the input records [31]. 
Blanchard's approach utilizes this data as input and associates this input data to a pixel in a figure. The algorithm is a well-organized way to visualize the typical and large data. Finally the use of these mention algorithm collectively lead to obtain an entirely unverified visual data mining instrument. Where the color mapping is data driven. The testing outcome of this approach offers visualization that permit the taking out of cluster. The unverified automation of the coloring allows us to nuance the attachment of a class [31]. The given paper [34] shows machine learning and data mining application for the prediction of drifts in technology skilled turnover rates of the employees. Then he used an algorithm which is the combination of two different algorithm i.e., SOM (self-organizing map) and BPN(back propagation neural network) [34]. This algorithm combines the advantages of SOM and BPN which applied on the expose properties associated to turnover trends cluster. With the help of this algorithm we come to know that this algorithm is the best algorithm for finding out the turnover of employees and also showing the factors which involve in increasing the rate of the employees turnover [34]. The author predicts a new intelligent approach which will forecast the frequent growth of software which is based on the functional networks forecasting framework [37]. There are lots of other methods which forecast the prediction of the software development. But all these failed because these have number of drawbacks like how to deal with the uncertainties. The planned approach has high tendency to deal with the grown environment of recent software progress [37]. The result shows that this method is far better than then other approaches; its performance is sure and gives us a smallest MAPE value [37]. The aim of this paper [43] is to examine the scalability of PNN (probabilistic neural network) through localization, a chain gradient tuning and parallelism. As PNN model is working in parallel so three well know approaches are studied here. Two fast approximation solutions are proposed by author in this paper. The main aim of this paper is to accelerate the PNN model with the help of 24 processors. And the result obtained reveals that PNN training along with subtractive clustering approaches and cross validation can amazingly escalate 24 times [43]. The 2nd issue is how to eliminate the sigma parameter without major loss in PNN performance. Clustering within classes the most representative points are selected. Which results a localized PNN having tiny pattern Neuron Size and excellent performance, which is 10 times faster as compare to that of original version? For the most excellent PNN architecture, tuning can performed to using chain gradient to test it [43]. The author is dealing with a major issue of prediction for software quality [46]. For resolving this hurdle he introduces an interpretable neural network model. This model consists upon a three layered feed forward neural network having sigmoid in its buried units. The output unit is having identity function and the model is trained accordingly. From trained neural network for the extraction of the rules he makes use of the clustering genetic algorithm [46]. For the detection of the fault prone software the rules extracted from the trained neural network are gathered. And then the rules are compared. The rules of trained neural network are compared with the rule of predicting results. The results show that trained neural network rules a bit accurate as compare to that of predicting results but predicting results are more understandable [46].

Table 6.1. Several Related Studies that Deal with Neural Network and Data Mining for using in Different Applications

\begin{tabular}{|c|c|c|c|c|}
\hline Ref. & Author Name & Title of Paper & $\begin{array}{c}\text { Feed } \\
\text { Forward }\end{array}$ \\
\hline$[23]$ & $\begin{array}{c}\text { QU Zhiming HOU } \\
\text { Wei }\end{array}$ & $\begin{array}{c}\text { Application of Combined Grey Neural Network and } \\
\text { Data Mining in Information Technology Education }\end{array}$ & $\begin{array}{c}\text { raining samples and least } \\
\text { square method }\end{array}$ \\
\hline$[9]$ & $\begin{array}{c}\text { Taeho Hong, Ingoo } \\
\text { Han. }\end{array}$ & $\begin{array}{c}\text { Knowledge-based data mining of news information on } \\
\text { the internet using Cognitive Maps and Neural Network }\end{array}$ & KBNMinner \\
\hline$[30]$ & $\begin{array}{c}\text { Stephen R. } \\
\text { mounce,henrietteS.je }\end{array}$ & $\begin{array}{c}\text { T-RFLP profiles from urban water system sampling } \\
\text { using SOM maps }\end{array}$ & ANN layered based \\
\hline
\end{tabular}




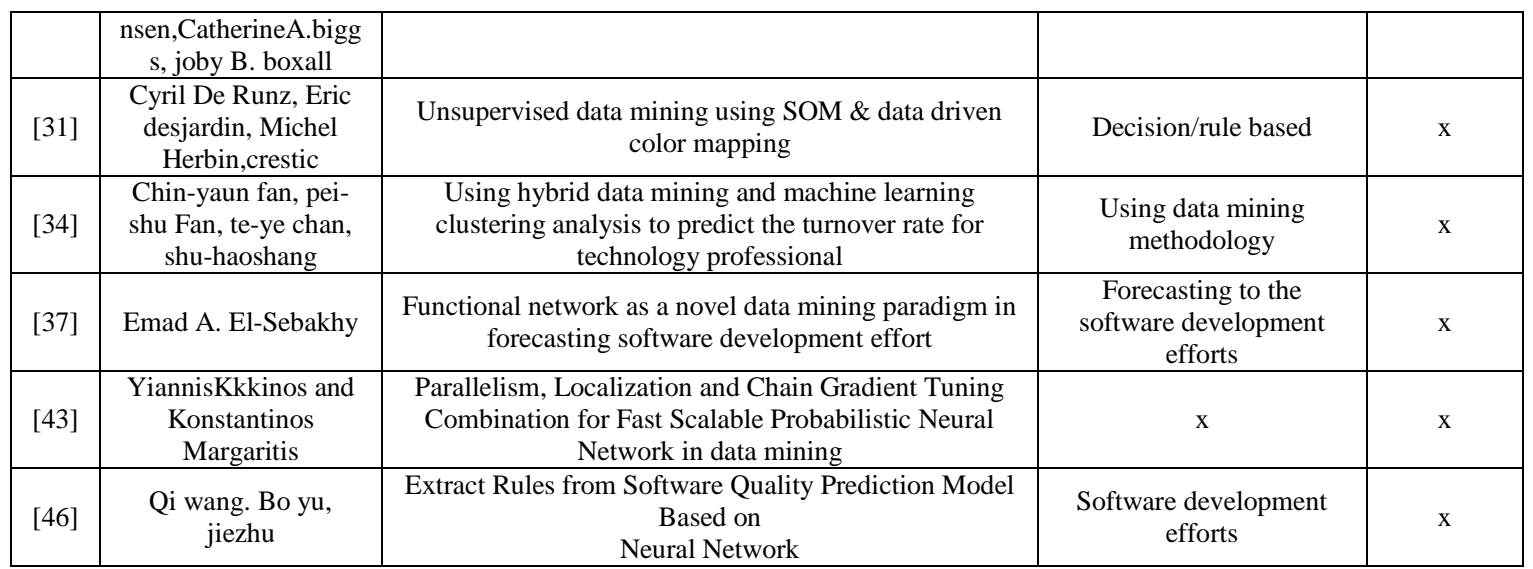

Table 6.2. Related Algorithms that Deal with Neural Network and Data Mining for using in Different Applications

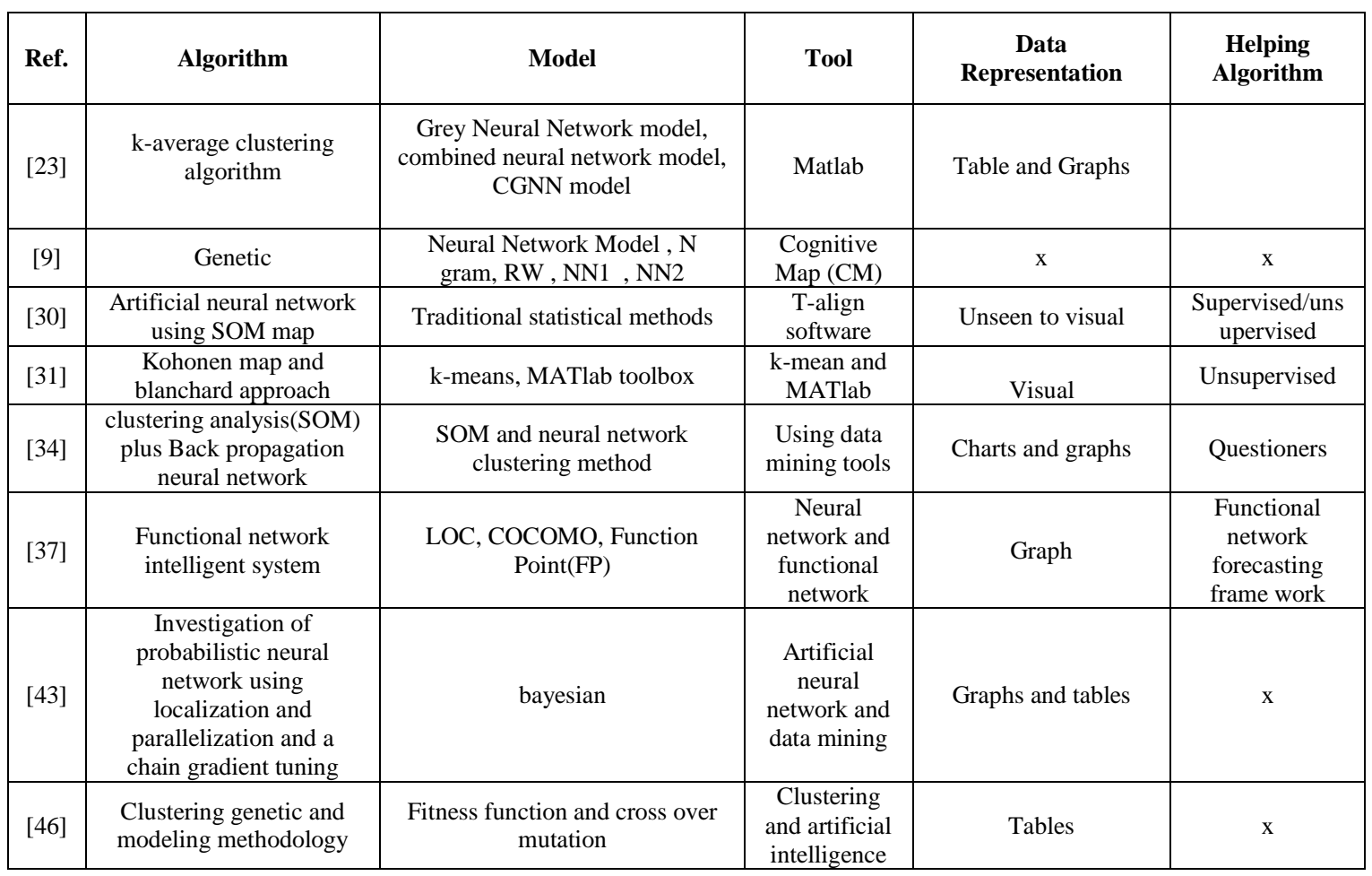

Table 6.3. Advantages, Techniques, Datasets, Model and Tools of the Different Studies

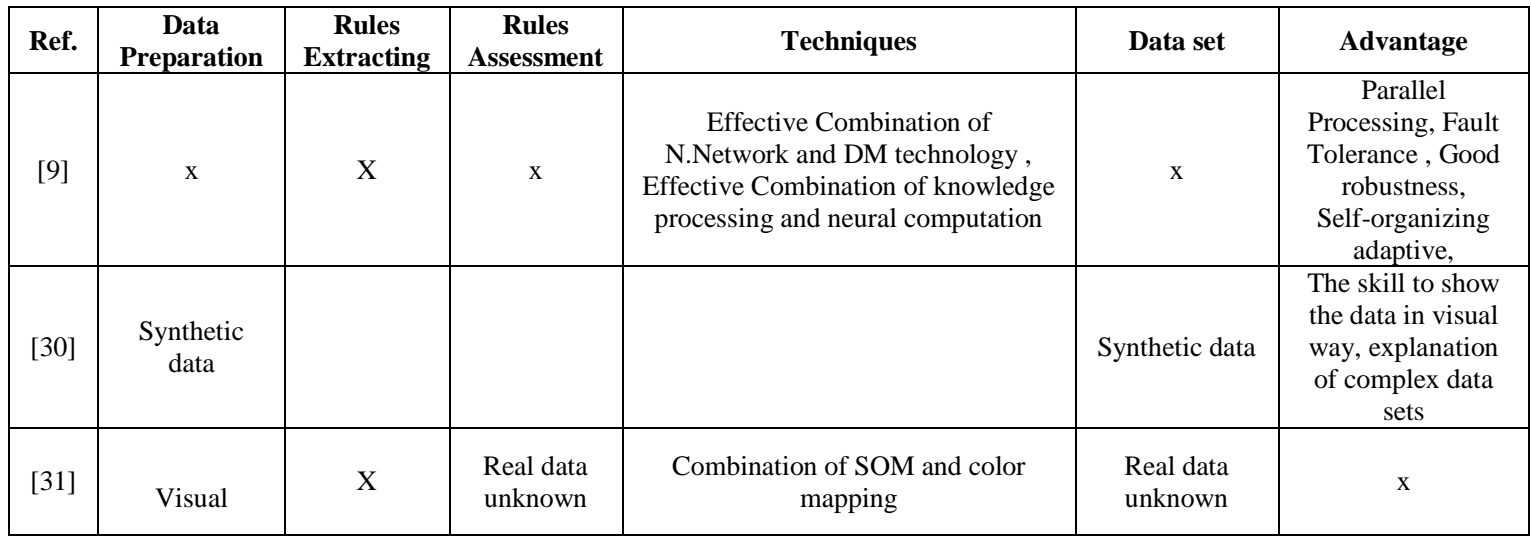




\begin{tabular}{|c|c|c|c|c|c|c|}
\hline [34] & $\begin{array}{c}\text { Charts and } \\
\text { graphs }\end{array}$ & $\mathrm{X}$ & $\mathrm{x}$ & Data mining & Real time data & $\mathrm{x}$ \\
\hline$[37]$ & Graphs & $\mathrm{X}$ & $\mathrm{x}$ & $\begin{array}{c}\text { Forecasting to the software } \\
\text { development efforts }\end{array}$ & predictions & $\begin{array}{c}\text { To use different } \\
\text { independent other } \\
\text { than polynomial to } \\
\text { use for data bases }\end{array}$ \\
\hline$[43]$ & $\begin{array}{c}\text { Graphs and } \\
\text { tables }\end{array}$ & $\mathrm{X}$ & $\mathrm{x}$ & $\mathrm{x}$ & Rules & $\mathrm{x}$ \\
\hline$[46]$ & Tables & $\mathrm{X}$ & $\mathrm{x}$ & Software development & Rules & $\mathrm{x}$ \\
\hline
\end{tabular}

\section{Artificial Neural Network and Data Mining}

In this paper [24] the author tells us that the elementary function of neural system is to learn intelligently from some precise model, which is called neurons. Due to the capability of pattern adaptive that may be used to judge well model and old model [24]. They are many characteristic of neural system such as uniqueness, noise tolerance, autonomous, and distributed detection. Motivated by neural network system, during last decade the artificial neural network has emerged. It is provoke by many researcher to study, built, and design neural models for a variety of application areas. ANN can be defines as adoptive model that is motivated by neural network, observer principle and mechanisms and observed neural functions. Association rule mining is most important techniques of data mining. The aim of association rule is to polish interesting association, correlation in sets of aims in other transaction databases and daturn repositories [24]. Association rule is extensively used in several regions like inventory control, market analysis, risk management and telecommunication. Artificial neural network is extensively used algorithm for association rule mining [24]. In this paper [25] the author tells us that that how to apply ANN in data mining techniques. It is suitable for solving data mining problem because of its feature of self-organization adaptive, distributed storage, parallel processing and good robustness and high amount of fault tolerance. To enhance the capability of data mining process artificial neural network plays a very exciting role in the field of Data mining. The result of such a united tool provides an intelligent and valuable insight for planning and decision making in all sphere [25]. The huge amount of data is stored in databases and files and other repositories, it is very important to develop a powerful capital for analysis, and also for the interested knowledge extraction that help in decision tree. So the data mining is the process of predictive information and extraction of hidden from the large database [25]. This paper [28] is based on adoptive neural network model for financial study. Data mining plays central role in finding buried predictive information from bulky catalog [28]. Artificial neural network which is commonly used by data mining technique, is an algorithm used for this purpose. This proposed approach has been tested with function approximation and stock market moment study. And from these experimental data we can wind up that the future approach is much better to existing standard ANN for the use of data mining [28]. And we can see that our new ANN with NAF can boost trained speed, shrink network size and simulation error. And also provide us more promising outcomes [28]. In this paper the author focuses on the ANN and finds out different terms which are responsible for making ANN system more intelligent [50]. The author is looking forward and finding different ways for optimizing ANN based on classification methods. In this paper the author makes use of three standard data for computing the accuracy. The experimental results show that the system gave high accuracy [50]. 
Table 7.1. Several Related Studies that Deal with Neural Network and Data Mining for using in Different Applications

\begin{tabular}{|c|c|c|c|}
\hline Ref. & Author name & Title of Paper & Method \\
\hline$[24]$ & Liu Tiecheng & Optimizing Mining Association Rules based on Artificial Neural Network: & Classification \\
\hline$[25]$ & Ms.Smita.Nirkhi & Potential use of Artificial Neural Network in Data Mining & ANN, Decision trees: \\
\hline$[28]$ & $\begin{array}{c}\text { Shuxiangxu, Ming } \\
\text { Zang }\end{array}$ & An adoptive neural network model for financial analysis & NAF and ANN \\
\hline$[50]$ & Guan Ping & Exploitation of Minimum Risk System based on Artificial Neural Network & $\begin{array}{c}\text { To know about ANN } \\
\text { intelligence }\end{array}$ \\
\hline
\end{tabular}

Table 7.2. Advantages, Techniques, Datasets, Model and Tools of the Different Studies

\begin{tabular}{|c|c|c|c|c|c|}
\hline Ref. & Algorithm & Rules & Model & $\begin{array}{c}\text { Data } \\
\text { Presentation } \\
\end{array}$ & Advantage \\
\hline$[24]$ & $\begin{array}{l}\text { ANN algorithm, neural } \\
\text { clone selection, } \\
\text { algorithm }\end{array}$ & Association rule & $\begin{array}{c}\text { Construction models and } \\
\text { calibration computer models, } \\
\text { Computer sampling sequence mode }\end{array}$ & Tables & $\begin{array}{l}\text { Reduce the time } \\
\text { complexity }\end{array}$ \\
\hline$[25]$ & Genetic algorithms & $\begin{array}{l}\text { Classification, } \\
\text { Clustering, Regression, } \\
\text { Association rule } \\
\text { learning }\end{array}$ & SOM & Tables & $\begin{array}{l}\text { Reduce the time } \\
\text { complexity }\end{array}$ \\
\hline [28] & Artificial neural network & $\begin{array}{c}\text { To explore ANN with } \\
\text { NAF for financial } \\
\text { analysis }\end{array}$ & Neuron adoptive activation function & Graphs & $\begin{array}{l}\text { Reduce network } \\
\text { size and simulation } \\
\text { error } \\
\end{array}$ \\
\hline$[50]$ & Artificial neural network & Supervise/unsupervised & Neural Network & Tables & $\mathrm{x}$ \\
\hline
\end{tabular}

\section{Discussion}

The volume of data store in database increase rapidly and huge amount of information are hidden. The technology of mining the information from the huge volume of data (database) is called Data Mining. Neural network is very appropriate for solving problems of data mining because of its characteristics of good robustness, Self-organizing adaptive, parallel processing, and fault tolerance. Neural network have been used in many business application for pattern recognition, prediction and classification. Neural network have high ability for noisy data and high accuracy $[1,2,6,25]$. Neural network are non-linear statistical data modeling tools. This can be used to model complex relationships between input and output or to find patterns in data. It is very suitable for solving problems of data mining because it characteristic of parallel processing, high degree of fault tolerance, good robustness [7, 2]. The method of neural network is used for feature mining, pattern recognition, Clustering and classification. The model of neural network is dividing into three types such as feed-forward network, feedback network and self-organization network [1]. The author tells us that a huge amount of medical data is available but there is a lack of data analysis tool to extract useful knowledge from it. Unfortunately all doctors are not expert in all field of medical. Clinical results are often ready base on doctor's awareness and experience rather than on the knowledge masked in the database. Data mining have the ability to produce a knowledge-rich situation which can aid to improve the worth of clinical decision, due to this reason automatic medical diagnoses system is very useful by fetching all of them together. Genetic Algorithm is used to reduce the actual size of data which is enough for heart disease [2]. Artificial Neural Networks offer qualitative methods for business and economic systems that Traditional quantitative tools in statistics and econometrics cannot quantify due to the complexity in translating the systems into precise mathematical functions [3].Heart disease professional stores significant amounts of patient's data. It is necessary to scrutinize this data set to extract valuable knowledge. Knowledge of risky factors which are linked with the heart 
disease helps the care professional to identify the patients which have high risk of heart diseases [4]. In the market basket when a new transaction is added then for refreshing the ranking table we apply the artificial neural network. By data envelopment analysis it prevents to repeat all the process of problem. Minimum support and minimum confidence are the two factors of an association rule which determine the strength of a rule [5]. The combine tactic of Artificial neural network based network inference and Artificial neural network base data mining we have recognized 6 genes that associate with ER system in breast cancer. Only 4 are strongly associated with ER status [8]. The new ways to find information from news through internet and apply interest rate on the basis of this information, so we propose the Knowledge-Based News Miner (KBNMiner). According to prior knowledge it retrieves and search information of NEWS on internet, then we apply this information on the neural network model for the interest rate prediction [9]. The data mining is used to explore the potential factor of huge amount of data but still the preterm birth is still unclear. The preterm risks factor is related to smoking, drinking and work is also displayed in the result. It is necessary for the prospective fathers to adopt decent life style habit, so to keep safe his children from being born preterm [10]. The goal of BI/DM is to evaluate knowledge from raw data. They presents RMINER library which make it easy to use the $\mathrm{R}$ tool to solve the task of DM supervised [11, 13]. for time series forecast different computation techniques are used. Some parameter which effect the performance of neural network such as quality of data preprocessing and neural network structure. The aim of the neural network controller is to ratify all cartridges as a recurrent workflow for finding an ideal neural network for time series forecast [14].Fuzzy neural network technique is used as channel between symbolic and numerical data representation. By using fuzzy logic we can express knowledge in such a way which is natural for the people to understand. It increases the speedup of convergence of the network [15]. Data Strip Mining mine predictive models from data sets which has comparatively few data point and large number of potential input. This method uses neural network sensitivity analysis to find that which interpreter is mostly used in the problem. To determine the most important input to a system Neural Network sensitivity analysis was used as method, which allows removing some of the least critical input. To accurately determine the different neural model of the same system the author used a model cross validation as a method $[16,25]$. To model an output on one or more input variables a technique called supervised data mining technique is used, and these kind of models are used to forecast or predict future cases [17].the important task of data mining is Classification rules. A hybrid approach is presented which integrate the neural network and rough set to pit the classification rules from huge datasets. So to delete the noisy attribute in the table a neural network is trained. Those objects of also removed from the table which cannot be classified accurately by network [18]. In electrical power network the current signals and voltage reveal fluctuations in phase, amplitude, and frequency due to solid state device operation which are used for regularly used for power control [19]. Multilayer perception is very slow for the high dimensional datasets. CMAC Neural Network adaptation they have proposed for data mining. It works on real dataset. Which provide guaranteed convergence and fast training time [20]. The author uses the UCI machine learning repository and he has taken the benchmark dataset from it, and with respect to medoids he proposed to find the clusters and the sample has been trained by using Fuzzy redial basis function neural network which report very good result [21]. The neural network to DSS function is ensuing by scrutinizing the characteristic of problems and neural network of DSS [22]. The combination with neural network model and prediction model and CGNN model adopts the RBF neural network models and GM which plays a very vital role in analyzing user received data protection. Nonlinear dynamic and self-adopt system is a kind of neural network method. To overcome the series of problem in application data mining and grey system theory can be waged for each other. The effect of analyzing data safety is good by the combination of neural 
network and grey system in order to defend data from attack [23]. The elementary function of neural system is to learn intelligently from some precise model, which is called neurons. Due to the capability of pattern adaptive that may be used to judge well model and old model. They are many characteristic of neural system such as uniqueness, noise tolerance, autonomous, and distributed detection. The aim of association rule is to polish interesting association, correlation in sets of aims in other transaction databases and data repositories [24]. This algorithm is based on the idea that misused transactions are seen as a kind of rule. The advantage of this is, combining a number of misuse rules which leads us to shorten the rules and decrease the dependency. The other rules are called mining analog data. These rules are based on dealing with analog data. This algorithm leads us to high fraud detection and high confidence. This system is used in sequential as well. The advantage of this system is that the analog data first passes through analog check and then moves forward for sequential check, which leads us to high data correctness and high confidence as well [26]. This proposed approach has been tested with function approximation and stock market moment study. And from these experimental data we can wind up that the future approach is much better to existing standard ANN for the use of data mining [28]. It tells that ANN is combined with $\mathrm{RBF}$ (redial basis function) to recover the abnormal data. The ANN model is based on three layered architecture. Which takes data on input node then transform it to middle layer called hidden node then it moves toward the output node. This algorithm detects and recover the irregular parameters rapidly and efficiently [29]. They introduced selforganizing maps approach in neural network. The job of which is to collect DNA based molecular techniques and to analyze environmental samples. The main benefit of this approach is the capability to present the data in a visual way that offers effortless visualization and understanding of multi-dimensional and complex data sets [30]. The testing outcome of this approach offers visualization that permit the taking out of cluster. The author used is SOM(self-organizing map). This algorithm yields two dimensional and irregular representation of the input records [31, 32, 34]. The experimental outcomes of this algorithm prove that this algorithm is vastly valid in pattern recognition and is computationally efficient from this it can be accomplished that MTS-ANN algorithm can be effectively useful to dynamic environment for data-mining troubles [33]. Ensemble recursive rule extraction is basically mining of rules from the ensemble neural network. From this we can observe that the proposed approach produces higher recognition accuracy as compared to the individual neural network [35]. The author has predicted a novel approach the author used three techniques (artificial neural network, support vector machine and decision trees) the purpose of using these technique is to create regression and classification kind of models so that to review different methodologies prediction ability. This method proved that this approach is better way to present the future predictions and can provide a lot of accurate results than the previous predictions [36]. For the association of performance of the financial distress prediction; he makes use of the clustering and BPN modeling. So that to get an early alarm. From the results of the method he comes to know four major critical attributes. The 1st is that as more as we are using the factor analysis our result for clustering and BPN will be less accurate. 2nd is that that as soon as we get close to the actual financial distress, we will catch more precise outcome. 3rd is BPN has lower average rate of type ii errors as compare to the clustering model. In 4th the last stage the BPN provides a better and efficient prediction as that of the DM clustering approach [38]. The goal of this author is to divide woman in two categories i.e., the woman who has broad confirmations of having breast cancer are grouped into malignant and having no breast disease are grouped into benign. So the author tried to propose such a hybrid breast cancer diagnose system by joining together artificial neural network and MRAS. The main advantage of hybrid system is that it can save lots of implementation time which results in making shorten the time for on time decisions [39]. The author is cautious to know similarities and dissimilarities between two 
different schools of thoughts. He simply concluded that instead of using complex modeling technique the goal of analyzing is much important. So with the help of simpler model give us a good result just like complex one [40]. The work mentioned in this paper delivers a generalized procedure, which can be used for the problems in bioinformatics. The results are really impressive but the problem is that of producing a large amount of data. Combination of algorithm with the neural network for the purpose of extracting of information from the trained neural network is the best solution, which produces high accurate data along with that produces knowledge discovery [41]. The comparison of DM technique is shown with many other procedures like expert system and topographic threshold method (TT). The results show that DM technique provides more accurate data than that of the other methods. So it is obvious that for the study of the erroneous procedure and gully initiation a valuable technique is DM technique [42]. The main aim of this paper is to accelerate the PNN model with the help of 24 processors. And the result obtained reveals that PNN training along with subtractive clustering approaches and cross validation can amazingly escalate 24 times. Clustering within classes the most representative points are selected. This results a localized PNN having tiny pattern Neuron Size and excellent performance, which is 10 times faster as compare to that of original version [43]. The author is curious about getting high blood pressure data from a hospital data base. He is using back propagation algorithm in a multi-layered neural network. With the help of artificial intelligence approaches the hypothesis or activities of data is shown along with that formerly unknown data is exposed [44]. From trained neural network for the extraction of the rules he makes use of the clustering genetic algorithm. For the detection of the fault prone software the rules extracted from the trained neural network are gathered. The results show that trained neural network rules a bit accurate as compare to that of predicting results but predicting results are more understandable [46]. In data mining classification is a key subject to be focused. But dealing with incomplete survey then classification is an innovative subject [47]. The author focuses on the diagnosis and fault forecast methods of stream turbine which is totally based on the genetic and neural network. By comparing the novel approach to the traditional approach it is quite clear that has better performance and simple to design. The given system provide a good output with better confidence along with that it has strong ability of fault tolerant. The author presents a novel approach known as extension neural network approach to deal with the incomplete survey. This proposed approach is dealing with the supervised data. After comparing the result of the planned approach with other approaches, it clearly shows that this approach has the benefit of high accuracy over other approaches [49]. The author is looking forward and finding different ways for optimizing ANN based on classification methods. He makes use of three standard data for computing the accuracy. The experimental results show that the system gave high accuracy [50].

\section{Conclusion}

He told us that the use of neural network is very wide in data mining due to some characteristic like parallel performance, Self-organizing adaptive, robustness and fault tolerance. The method of neural network is used for feature mining, pattern recognition, Clustering and classification. The model of neural network is divided into three types such as feed-forward network, feedback network and self-organization network. It use neural network to find pattern in data. Genetic Algorithm is used to reduce the actual size of data which is enough for heart disease. It gives $99.2 \%$ accuracy. Artificial Neural Networks offer qualitative methods for business and economic systems that Traditional quantitative tools in statistics and econometrics cannot quantify due to the complexity in translating the systems into precise mathematical functions. For the training of artificial networks it needs supervised learning, Unsupervised Learning, Reinforcement Learning. The neural network can be dividing into following type recurrent neural network, Feed 
forward neural network. The algorithm used is Back propagation Algorithm. Neural network are non-linear statistical data modeling tools. This can be used to model complex relationships between input and output or to find patterns in data. As ANN algorithm is fast learning algorithm. In future using Data Mining technique ANN combines with other algorithm used for various purposes. ANN has high accuracy and high pattern recognition. Still work needs to be done to make ANN more intelligent.

\section{References}

[1] P. Gaur, "Neural Networks in Data Mining", International Journal of Electronics and Computer Science Engineering (IJECSE, ISSN: 2277-1956), vol. 1, (2012), pp. 1449-1453.

[2] J. Soni, U. Ansari, D. Sharma and S. Soni, "Predictive data mining for medical diagnosis: An overview of heart disease prediction", International Journal of Computer Applications, vol. 17, (2011), pp. 43-48.

[3] A. Ali, "A Concise Artificial Neural Network in Data Mining", International Journal of Research in Engineering \& Applied Sciences, vol. 2, no. 2, (2012) February 12, pp. 418-428.

[4] M. Shouman, T. Turner and R. Stocker, "Using data mining techniques in heart disease diagnosis and treatment", Electronics, Communications and Computers (JEC-ECC), 2012 Japan-Egypt Conference on: IEEE, (2012), pp. 173-177.

[5] A. Niknafs and S. Parsa, "A neural network approach for updating ranked association rules, based on data envelopment analysis", Artif. 1ntell., vol. 4, (2011), pp. 279-287.

[6] H. Lu, R. Setiono and H. Liu, "Effective data mining using neural networks", Knowledge and Data Engineering, IEEE Transactions, vol. 8, (1996), pp. 957-961.

[7] Z. Chen, "Research of Data Mining Based on Neural Network", E-Product E-Service and EEntertainment (ICEEE), 2010 International Conference on: IEEE, (2010), pp. 1-3.

[8] G. K. Dhondalay, C. Lemetre and G. R. Ball, "Modeling estrogen receptor pathways in breast cancer using an Artificial Neural Networks based inference approach", Biomedical and Health Informatics (BHI), 2012 IEEE-EMBS International Conference on: IEEE, (2012), pp. 948-951.

[9] T. Hong and I. Han, "Knowledge-based data mining of news information on the Internet using cognitive maps and neural networks", Expert Systems with Applications, vol. 23, (2002), pp. 1-8.

[10] H.-Y. Chen, C.-H. Chuang, Y.-J. Yang and T.-P. Wu, "Exploring the risk factors of preterm birth using data mining", Expert Systems with Applications, vol. 38, (2011), pp. 5384-5387.

[11] P. Cortez, "Data mining with neural networks and support vector machines using the R/rminer tool", Advances in Data Mining. Applications and Theoretical Aspects: Springer, (2010), pp. 572-583.

[12] M. Kamrunnahar and M. Urquidi-Macdonald, "Prediction of corrosion behavior using neural network as a data mining tool”, Corrosion Science, vol. 52, (2010), pp. 669-677.

[13] P. Cortez, "Data mining with neural networks and support vector machines using the R/rminer tool", Advances in Data Mining. Applications and Theoretical Aspects: Springer, (2006), pp. 572-583.

[14] E. Ogasawara, L. Murta, G. Zimbrao and M. Mattoso, "Neural networks cartridges for data mining on time series", Neural Networks, 2009. IJCNN 2009. International Joint Conference on: IEEE, (2009), pp. 2302-2309.

[15] Y. Frayman and L. Wang, "Data mining using dynamically constructed recurrent fuzzy neural networks", Research and Development in Knowledge Discovery and Data Mining: Springer, (1998), pp. $122-131$

[16] R. H. Kewley, M. J. Embrechts and C. Breneman, "Data strip mining for the virtual design of pharmaceuticals with neural networks", Neural Networks, IEEE Transactions, vol. 11, (2000), pp. 668679.

[17] R. Li and Z.-o. Wang, "Mining classification rules using rough sets and neural networks", European Journal of Operational Research, vol. 157, (2004), pp. 439-448.

[18] R. Li and Z.-o. Wang, "Mining classification rules using rough sets and neural networks", European Journal of Operational Research, vol. 157, (2004), pp. 439-448.

[19] P. K. Dash, M. Nayak, M. R. Senapati and I. W. Lee, "Mining for similarities in time series data using wavelet-based feature vectors and neural networks", Engineering Applications of Artificial Intelligence, vol. 20, (2007), pp. 185-201.

[20] F. Palacios, X. Li and L. E. Rocha, "Data mining based on CMAC neural networks", Electrical and Electronics Engineering, 2006 3rd International Conference, IEEE, (2006), pp. 1-4.

[21] T. Nagabhushan, H. Ko, J. Park, S. Padma and Y. Nijagunarya, "Classification of Symbolic Objects Using Adaptive Auto-Configuring RBF Neural Networks", Information Technology Convergence, 2007. ISITC 2007. International Symposium IEEE, (2007), pp. 22-26.

[22] X. Qian and X. Wang, “A New Study of DSS Based on Neural Network and Data Mining”, E-Business and Information System Security, 2009. EBISS'09. International Conference IEEE, (2009), pp. 1-4.

[23] Q. Zhiming and H. Wei, "Application of Combined Grey Neural Network and Data Mining in Information Technology Education", Education Technology and Training, 2009. ETT'09. Second International Conference on: IEEE, (2009), pp. 163-166. 
[24] L. Tiecheng, "Optimizing mining association rules based on Artificial Neural Network", World Automation Congress (WAC), 2012: IEEE, (2012), pp. 1-4.

[25] S. Nirkhi, "Potential use of artificial neural network in data mining", Computer and Automation Engineering (ICCAE), 2010 The 2nd International Conference on: IEEE, (2010), pp. 339-343.

[26] R. Brause, T. Langsdorf and M. Hepp, "Neural data mining for credit card fraud detection", Tools with Artificial Intelligence, 1999. Proceedings. 11th IEEE International Conference IEEE, (1999), pp. 103106.

[27] H. Lu, R. Setiono and H. Liu, "Effective data mining using neural networks", Knowledge and Data Engineering, IEEE Transactions, vol. 8, (1996), pp. 957-961.

[28] S. Xu and M. Zhang, "Data mining-an adaptive neural network model for financial analysis", Information Technology and Applications, 2005. ICITA 2005. Third International Conference on: IEEE, (2005), pp. 336-340.

[29] Q. Liu, F. Bao, H. Xu and B. Xia, "The research on data analyzing and processing of solid ducted rocket test based on artificial neural network method", Consumer Electronics, Communications and Networks (CECNet), 2012 2nd International Conference on: IEEE, (2012), pp. 2183-2186.

[30] S. R. Mounce, H. S. Jensen, C. A. Biggs and J. B. Boxall, "Data mining T-RFLP profiles from urban water system sampling using self-organizing maps", Natural Computation (ICNC), 2012 Eighth International Conference on: IEEE, (2012), pp. 212-216.

[31] C. De Runz, E. Desjardin and M. Herbin, "Unsupervised visual data mining using self-organizing maps and a data-driven color mapping", Information Visualisation (IV), 2012 16th International Conference on: IEEE, (2012), pp. 241-245.

[32] J. Malone, K. McGarry, S. Wermter and C. Bowerman, "Data mining using rule extraction from Kohonen self-organising maps", Neural Computing \& Applications, vol. 15, (2006), pp. 9-17.

[33] C.-L. Huang, T.-S. Hsu and C.-M. Liu, "The Mahalanobis-Taguchi system-Neural network algorithm for data-mining in dynamic environments", Expert systems with applications, vol. 36, (2009), pp. 54755480.

[34] C.-Y. Fan, P.-S. Fan, T.-Y. Chan and S.-H. Chang, "Using hybrid data mining and machine learning clustering analysis to predict the turnover rate for technology professionals", Expert Systems with Applications, vol. 39, (2012), pp. 8844-8851.

[35] A. Hara and Y. Hayashi, "A new neural data analysis approach using ensemble neural network rule extraction”, Artificial Neural Networks and Machine Learning-ICANN 2012: Springer, (2012), pp. 515522.

[36] D. Delen, D. Cogdell and N. Kasap, "A comparative analysis of data mining methods in predicting NCAA bowl outcomes", International Journal of Forecasting, vol. 28, (2012), pp. 543-552.

[37] E. A. El-Sebakhy, "Functional networks as a novel data mining paradigm in forecasting software development efforts", Expert Systems with Applications, vol. 38, (2011), pp. 2187-2194.

[38] W.-S. Chen and Y.-K. Du, "Using neural networks and data mining techniques for the financial distress prediction model”, Expert Systems with Applications, vol. 36, (2009), pp. 4075-4086.

[39] S.-M. Chou, T.-S. Lee, Y. E. Shao and I.-F. Chen, "Mining the breast cancer pattern using artificial neural networks and multivariate adaptive regression splines", Expert Systems with Applications, vol. 27, (2004), pp. 133-142.

[40] M. Karlaftis and E. Vlahogianni, "Statistical methods versus neural networks in transportation research: Differences, similarities and some insights", Transportation Research Part C: Emerging Technologies, vol. 19, (2011), pp. 387-399.

[41] A. Browne, B. D. Hudson, D. C. Whitley, M. G. Ford and P. Picton, "Biological data mining with neural networks: Implementation and application of a flexible decision tree extraction algorithm to genomic problem domains", Neurocomputing, vol. 57, (2004), pp. 275-293.

[42] T. Svoray, E. Michailov, A. Cohen, L. Rokah and A. Sturm, "Predicting gully initiation: comparing data mining techniques, analytical hierarchy processes and the topographic threshold", Earth Surface Processes and Landforms, vol. 37, (2012), pp. 607-619.

[43] Y. Kokkinos and K. Margaritis, "Parallelism, localization and chain gradient tuning combinations for fast scalable probabilistic neural networks in data mining applications", Artificial Intelligence: Theories and Applications: Springer, (2012), pp. 41-48.

[44] M. M. Eugène, K. K. Pierre, M. B. Steve and M. M. Didier, "Datamining and networks neuronal extracting knowledge from high pressure data patients", International journal of computer science issues (ijcsi), vol. 9, (2012).

[45] W.-S. Chen and Y.-K. Du, "Using neural networks and data mining techniques for the financial distress prediction model", Expert Systems with Applications, vol. 36, (2009), pp. 4075-4086.

[46] Q. Wang, B. Yu and J. Zhu, "Extract rules from software quality prediction model based on neural network", Tools with Artificial Intelligence, 2004. ICTAI 2004. 16th IEEE International Conference on: IEEE, (2004), pp. 191-195.

[47] C. Lu, X.-W. Li and H.-B. Pan, "Application of Extension Neural Network for Classification with Incomplete Survey Data", Innovative Computing, Information and Control, 2006. ICICIC'06. First International Conference on: IEEE, (2006), pp. 190-193. 
[48] L. Wang and T. Sui, "Application of data mining technology based on neural network in the engineering", Wireless Communications, Networking and Mobile Computing, 2007. WiCom 2007. International Conference on: IEEE, (2007), pp. 5544-5547.

[49] Q. Guo and M. Zhang, "A novel approach for fault diagnosis of steam turbine based on neural network and genetic algorithm", Neural Networks, 2008. IJCNN 2008.(IEEE World Congress on Computational Intelligence). IEEE International Joint Conference on: IEEE, (2008), pp. 25-29.

[50] G. Ping, "Exploitation of minimum risk system based on Artificial Neural Network", IT in Medicine and Education (ITME), 2011 International Symposium on: IEEE, (2011), pp. 508-511.

\section{Authors}

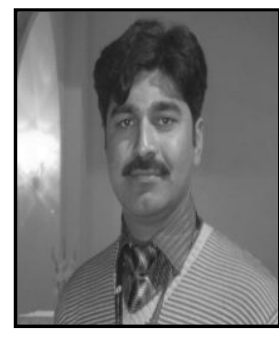

Muhammad Arif is a PhD student at Faculty of CS and IT, University of Malaya. Currently he is working on Medical image Processing. His research interests include image processing, E learning, Artificial intelligence and data mining. He joined UM as a Bright Spark Scholar in September 2013 for the period of 3 years. Before this he completed masters and bachelor degrees in Pakistan. He received his BS degree in Computer Science from University of Sargodha, Pakistan in 2011. He obtained his MS degree in Computer Science from COMSATS Islamabad 2013 Pakistan.

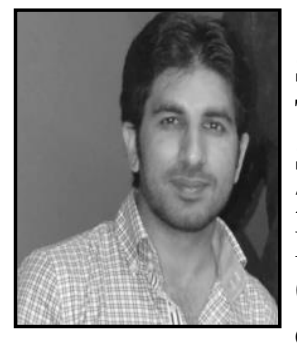

Khubaib Amjad Alam is a Ph.D. candidate at Department of Software Engineering, Faculty of Computer Science and Information Technology, University of Malaya, under the prestigious Bright Spark Fellowship. He received Master of Computer Science degree in 2013 from Comsats Institute of Information Technology, Pakistan. His current research interests are Business Process Management (BPM); Service oriented architecture (SOA), Web services, distributed systems, Change management, Maintenance and Evolution issues of Enterprise level software systems and engineering applications of soft methodologies.

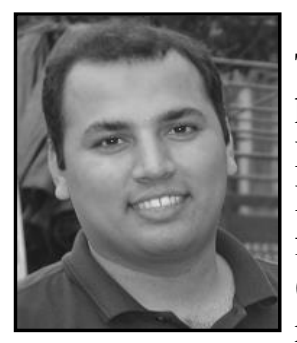

Mehdi Hussain received his BS degree in Computer Science from The Islamia University Bahawalpur, Pakistan in 2005. He obtained his MS degree in Computer Science from SZABIST Islamabad 2011 Pakistan. He has 8 years working experience in a renewed Software House (Streaming Networks (private)). He recently selected as funded scholar at National University of Science and Technology (NUST) under faculty development program 2014. Presently he is research scholar at University of Malaya, Malaysia. Research interests are multimedia security, steganography, data mining. He can be reached atmehdi141@hotmail.com. 